Journal of the Science of

Food and Agriculture

\title{
Phytochemicals determination and classification in purple and red fleshed potato tubers by analytical methods and near-infrared spectroscopy
}

\begin{tabular}{|r|l|}
\hline Journal: & Journal of the Science of Food and Agriculture \\
\hline Manuscript ID: & JSFA-15-0181.R1 \\
\hline Wiley - Manuscript type: & Research Article \\
\hline Date Submitted by the Author: & n/a \\
\hline Complete List of Authors: & $\begin{aligned} \text { TIERNO, ROBERTO; NEIKER, PLANT PRODUCTION } \\
\text { LOPEZ, AINARA; UPNA, AGRICULTURAL PROJECTS } \\
\text { Patrick, Riga; Basque Institute for Agricultural Research and Development } \\
\text { (NEIKER), Department of Plant Production and Protection } \\
\text { Arazuri, Silvia; Universidad Pública de Navarra, Proyectos e Ingeniería } \\
\text { Rural:Mecatrónica Agraria } \\
\text { Jaren, Carmen; Universidad Pública de Navarra, Deprtament of Proyect and } \\
\text { Rural Engineering } \\
\text { BENEDICTO, LEIRE; NEIKER, PLANT PRODUCTION } \\
\text { RUIZ DE GALARRETA GOMEZ, JOSE IGNACIO; NEIKER, PLANT } \\
\text { PRODUCTION }\end{aligned}$ \\
\hline Key Words: & $\begin{array}{l}\text { Soluble phenolics, monomeric anthocyanins, carotenoids,, vitamin C, NIRS, } \\
\text { Solanum tuberosum L. }\end{array}$ \\
\hline \multicolumn{2}{|l}{} \\
\hline
\end{tabular}

This is the peer reviewed version of the following article: Tierno, R. , López, A. , Riga, P. , Arazuri, S. , Jarén, C. , Benedicto, L. and Ruiz de Galarreta, J. I. (2016), Phytochemicals determination and classification in purple and red fleshed potato tubers by analytical methods and near infrared spectroscopy. J. Sci. Food Agric., 96: 1888-1899. doi:10.1002/jsfa.7294, which has been published in final form at https://doi.org/10.1002/jsfa.7294. This article may be used for non-commercial purposes in accordance with Wiley Terms and Conditions for Use of Self-Archived Versions. 
1 Phytochemicals determination and classification in purple and red fleshed

2 potato tubers by analytical methods and near-infrared spectroscopy

3

4 R. Tierno ${ }^{1}$, A. López ${ }^{2}$, P. Riga ${ }^{1}$, S. Arazuri ${ }^{2}$, C. Jarén ${ }^{2}$, L. Benedicto ${ }^{1}$, J. I. Ruiz de

5 Galarreta ${ }^{1}$

6

$7 \quad{ }^{1}$ NEIKER-Tecnalia. The Basque Institute for Agricultural Research and Development.

8 PO. Box. 46 E-01080. Vitoria. Spain.

$9{ }^{2}$ Department of Agricultural Projects and Engineering, Universidad Pública de Navarra,

10 Campus de Arrosadía 31006. Navarra. Spain.

11

12 Corresponding author.

13 Jose Ignacio Ruiz de Galarreta

14 Tel: +34-945-121313

15 Fax: $+34-945-281422$

16 E-mail: jiruiz@neiker.net

17 


\section{Abstract}

\section{BACKGROUND}

20 Over the last two decades, the attractive colours and shapes of pigmented tubers and the

21 increasing concern about the relationship between nutrition and health are contributing to

22 the expansion of their consumption and specialty market. Thus, we have quantified the

23 concentration of health promoting compounds such as soluble phenolics, monomeric

24 anthocyanins, carotenoids, vitamin $\mathrm{C}$, and hydrophilic antioxidant capacity, in a collection

25 of 18 purple and red fleshed potato accessions.

\section{RESULTS}

27 Cultivars and breeding lines high in vitamin $\mathrm{C}$, such as Blue Congo, Morada and Kasta,

28 have been identified. Deep purple cultivars Violet Queen, Purple Peruvian and Vitelotte

29 showed high levels of soluble phenolics, monomeric anthocyanins, and hydrophilic

30 antioxidant capacity, whereas relatively high carotenoid concentrations were found in

31 partially yellow coloured tubers, such as Morada, Highland Burgundy Red, and Violet

32 Queen.

\section{CONCLUSION}

34 The present characterization of cultivars and breeding lines with high concentrations of 35 phytochemicals is an important step both to support the consideration of specialty potatoes 36 as a source of healthy compounds, and to obtain new cultivars with positive nutritional 37 characteristics. Moreover, by using near-infrared spectroscopy a non-destructively 38 identification and classification of samples with different levels of phytochemicals is 39 achieved, offering an unquestionable contribution to potato industry for future automatic 40 discrimination of varieties. 
41

42 Keywords: soluble phenolics, monomeric anthocyanins, carotenoids, vitamin C, NIRS, 43 Solanum tuberosum L.

44

45

46

47

48

49 Total soluble phenolics and monomeric anthocyanins found in certain purple potato

50 cultivars were comparable to those of blueberries

51

52 Soluble phenolics, monomeric anthocyanins and hydrophilic antioxidant capacity of potato 53 tubers were correlated.

54

55 Specialty potatoes can improve human diet

56

57 A classification of varieties according to their phytochemicals content is achieved by using 58 non-destructive near-infrared reflectance spectroscopy coupled with chemometrics. 
61

62

63 Potatoes are an excellent source of vitamins and phytochemicals, such as vitamin C,

64 phenolic acids, flavonoids and carotenoids, which may provide a wide range of health

65 benefits ${ }^{1}$. Despite the fact that there are important differences between genotypes, potatoes

66 may contribute to about $44 \%$ of the recommended daily intake of vitamin $\mathrm{C}^{2}$ depending on

67 the diet. Among other things, this potent reducing agent acts as an antioxidant in the body,

68 cofactor for numerous enzymes and also plays an important role in increasing the

69 bioavailability of iron ${ }^{3}$.

70

71 have shown beneficial properties. Phenolics are commonly classified into three important

72 groups: phenolic acids, flavonoids and tannins ${ }^{4}$. The major phenolic acid in potato is

73 chlorogenic acid ${ }^{5}$. Anthocyanins are phenolic pigments which constitute the main subclass

74 among flavonoids. The most common anthocyanidins (the de-glycosylated forms of

75 anthocyanins) found in potatoes are malvidin, petunidin, delphinidin and peonidin in purple

76 tubers and pelargonidin in red ones ${ }^{6}$. Different aglycones and sugar moieties determine

77 their bioavailability and potential health effects ${ }^{7}$. A study of 74 Andean potato landraces

78 revealed a wide variability for total phenolic compounds from 1.12 to $12.4 \mathrm{~g} \mathrm{GAE} \mathrm{kg}^{-1} \mathrm{DW}$

79 and antioxidant capacity from 0.0283 to $0.251 \mathrm{~mol} \mathrm{TE} \mathrm{kg}^{-1} \mathrm{DW}{ }^{8}$ thus showing the

80 important genotype effect on the content of health promoting phytochemicals.

81 Carotenoids are a widespread family of lipophilic organic pigments ${ }^{9}$. Based on

82 epidemiological studies a positive link is suggested between higher dietary intake and tissue

83 concentrations of carotenoids and lower risk of chronic diseases ${ }^{10}$. The orange flesh colour

84 found in some potatoes is due to zeaxanthin whereas lutein concentration correlates with 
85 the intensity of yellow coloration. Cultivated diploid potatoes derived from Solanum 86 stenotonum Juz. \& Bukasov and Solanum phureja Juz. \& Bukasov have been reported to be 87 a great source of zeaxanthin and lutein ${ }^{11-13}$.

88 Purple and red fleshed potato cultivars are attractive to consumers. Besides their exotic 89 pigmentation, coloured genotypes show significantly higher contents of phenolic 90 compounds ${ }^{14-15}$. Specialty potato food products, such as coloured chips, crisps, purees, 91 canned potatoes, and ready meals are becoming more and more widespread. With varying 92 degrees of success, some companies and research centres are trying to develop new 93 coloured cultivars to support increasing demand of specialty potato market, giving 94 particular emphasis on their superior nutritional profile, attractive colours and different 95 textures. To this end, the selection of appropriate parents to be used in artificial crosses is 96 one of the main decisions faced by breeders. Thus the identification of promising genotypes 97 is a key step in potato breeding.

98 On the other hand, the analytical methods commonly employed to determine main 99 compounds of potatoes in order to identify valuable genotypes require a lot of time and are 100 destructive. Therefore, these methods seem to be not suitable for in-line applications in the 101 food industry ${ }^{16}$. Nowadays, there are non-destructive available technologies to perform 102 qualitative and quantitative analysis of food and food products. In this respect, Near103 infrared spectroscopy (NIRS) is considered one of the most advanced techniques 104 concerning non-destructive quality control of agricultural and food products ${ }^{17}$. It has been 105 successfully used for the quantitative analysis of many agricultural and food products 106 during the last decades ${ }^{18-19}$. However, NIR can also be used for qualitative analysis, where 107 the aim is to classify samples on the basis of its spectral features rather than estimate the 108 components present in them ${ }^{20}$. 
NIR applications for the prediction of potato constituents are a common practice 110 nowadays; however, in this study taking into account that the number of samples is rather 111 small and they are very specific, it becomes very challenging to develop a robust model for 112 the prediction of phytochemicals. Other authors were able to determine the total phenolic 113 content of whole and lyophilized tubers while working with a large number of samples 114 including yellow, red and purple varieties ${ }^{21-22}$.

115 Despite that quantitative analyses of potatoes are widely extended, literature 116 concerning qualitative analysis is not as much to the best of our knowledge. Some authors 117 have focused in the classification of potato tubers according to their chemical components. 118 Thus, in a research developed by Fernández-Ahumada et al. ${ }^{23}$, a discriminant analysis was 119 performed in order to classify samples in two categories regarding to their protein content. 120 The results obtained demonstrated the accuracy of NIR to classify potato samples in groups 121 of low and high protein content.

122 In this study, we have analysed the concentration of phenolic compounds, monomeric 123 anthocyanins, carotenoids, vitamin C, and hydrophilic antioxidant capacity by analytical 124 methods in a collection of 18 purple and red fleshed potato cultivars to classify samples in 3 125 groups (low, mid and high) according to their phytochemicals content by NIRS combined 126 with chemometric tools. 
128

129

130

131

132

133

134

135

136

137

138

139

140

141

142

143

144

145

146

147

148

149

150

\section{MATERIALS AND METHODS}

\section{Plant material and experimental conditions}

A collection of 18 purple and red fleshed potato cultivars and breeding lines were selected on the basis of the contrasting flesh colour of tubers (Table 1). Tubers were selected from potato accessions (Potato Germplasm Collection, NEIKER) grown during the year 2013 in a precise field trial in Arkaute (Alava) in the northeastern of Spain (550 masl) with humid climate and annual rainfall of about $800 \mathrm{~L} \mathrm{~m}^{-2}$. The soil with a clay loam texture was previously subjected to conventional wheat cropping. Plants were grown from mid May to mid October 2013 after pre-sowing fertilization with $800 \mathrm{~kg} \mathrm{ha}^{-1}$ (NPK 4-8-16). Watering was performed using an automatic spray irrigation system. After harvesting, potatoes were stored at $4{ }^{\circ} \mathrm{C}$ in a darkened cold room for one month.

\section{NIR spectral acquisition}

Prior to lyophilisation NIRS measurements were made in whole intact tubers (unpeeled and free of soil). No previous preparation of the samples was accomplished for spectral acquisition. Since the main objective in the near future is to implement these techniques for real time measurements in potato handling lines, it is considered essential to analysed the tubers as they are currently being manipulated in those lines. NIR spectral data were collected using a Luminar 5030 Miniature "Hand held" AOTF-NIR Analyzer (Brimrose, Baltimore, Maryland). It covers a spectral range between 1100 and $2300 \mathrm{~nm}$ with 601 points (2 nm steps) and was used in reflectance mode. Samples were scanned at four different points along the equatorial area and the average spectrum was used for the analysis. Each spectrum was an average of 50 scans. 
151 By measuring the samples in reflectance mode we obtained information from not only the

152 skin but also from the flesh. Lammertyn et al. ${ }^{24}$ proved that when a sample is irradiated in

153 the near-infrared spectral range, the light penetrates through the skin and the NIR

154 reflectance spectrum of samples contains information of the background. Moreover, they

155 concluded that the amount of information coming from the background exceeded that

156 coming from the skin. Those authors established a NIR penetration depth between 2 and 3

$157 \mathrm{~mm}$ in the 900-1900 $\mathrm{nm}$ range for apple. In another study developed by López et al. ${ }^{25}$

158 authors also found that NIR reflectance spectra of unpeeled potatoes in the 1100-2300 nm

159 range contained information of both skin and flesh.

\section{Sample preparation for chemical analysis}

162 Five raw tubers of each accession were washed and patted dry with paper towels, and

163 subsequently peeled and diced. Diced tubers were divided into two equal parts. One part

164 was frozen with liquid nitrogen, kept frozen at $-80^{\circ} \mathrm{C}$, and later freeze dried, milled by an

165 automatic mortar grinder, and stored at $-30^{\circ} \mathrm{C}$ until analysis. Lyophilisation was used for

166 the determination of dry matter content. Total soluble phenolics and total monomeric

167 anthocyanins were analysed using freeze dried tubers. Total carotenoids, vitamin C, and

168 hydrophilic antioxidant capacity were determined immediately using the fresh portion. All

169 assays were performed in triplicate.

171 Extraction and quantitative determination of vitamin C (VC)

172 Tubers were homogenized in oxalic acid $4 \%(1: 1 \mathrm{w} / \mathrm{v})$, until a homogeneous puree is 173 obtained $(1 \mathrm{~min})$ in a Palson blender at maximum speed $(1200 \mathrm{~W})$. To optimize the 174 homogenization, $20 \mathrm{~g}$ of puree were weighed in a $50 \mathrm{~mL}$ tube and a teaspoon of steel balls 
175 was added to each tube and re-homogenized in Bullet Blender (Next Advance) 15 minutes 176 at power 9. Then, samples were centrifuged at $3350 \mathrm{~g}, 10 \mathrm{~min}$. The supernatant was 177 preserved at $-80{ }^{\circ} \mathrm{C}$ until analysis. Under these conditions, vitamin $\mathrm{C}$ was stable for at least 178 two months (data not shown). On the day of analysis, the samples were thawed submerging 179 in cold tap water for 15 minutes. Samples were shacked in a vortex, centrifuged 5 min at $180372 \mathrm{~g}$ and filtered with glass fibre filter of $1 \mu \mathrm{m}$. The filtered extract was oxidized with $1810.5 \%$ aqueous diclorophenol-indophenol solution and subsequently mixed with 2\% 2, 4182 dinitrophenylhydrazine in $70 \%$ sulphuric acid to allow the formation of hydrazones. The 183 hydrazones were extracted with ethyl acetate: acetic acid 98:2 and this orange coloured 184 extract was applied directly onto the HPTLC plates (nano silica gel F 254, $20 \times 10 \mathrm{~cm}$, 185 Fluka) by the mean of the semi-automatic sampler LINOMAT 5 (CAMAG). 186 Chromatography was developed in horizontal chamber as described in the application notes

187 A. $10.5^{26}$. The total ascorbic acid was measured at $510 \mathrm{~nm}$ by CAMAG TLC Scanner 3 188 and was quantified with the Wincats software. Results were expressed as g of vitamin C per $189 \mathrm{~kg}$ fresh weight.

191 Extraction and quantitative determination of soluble phenolics (TSP)

192 Phenolics were extracted from lyophilized powder $(1 \mathrm{~g})$ with $10 \mathrm{~mL} \mathrm{MeOH}: \mathrm{H}_{2} \mathrm{O}(70: 30$, $193 \mathrm{v} / \mathrm{v})$. The solid was suspended by shaking in a vortex for $1 \mathrm{~min}$. The mixture was 194 centrifuged at $7730 \mathrm{~g}$ for $10 \mathrm{~min}$ at $4{ }^{\circ} \mathrm{C}$, and the supernatant containing the extracted 195 phenolics was collected. The extraction operation was repeated twice again with the pellet 196 and the final volume carried to $30 \mathrm{~mL}$. Phenolic compounds were quantified following the 
197 method described by Medina ${ }^{27}$. Results were expressed as g Gallic acid equivalents per kg 198 fresh weight.

199

200 Extraction and quantitative determination of monomeric anthocyanins (TMA)

201 Monomeric anthocyanins were extracted and quantified by the $\mathrm{pH}$ differential method ${ }^{28}$. 202 Anthocyanins were extracted from lyophilized powder $(0.25 \mathrm{~g})$ with $10 \mathrm{~mL} \mathrm{MeOH}: \mathrm{HCl}$ $203(99: 1, \mathrm{v} / \mathrm{v})$. The solid was suspended by shaking in a vortex for $1 \mathrm{~min}$. The mixture was 204 centrifuged at $7730 \mathrm{~g}$ for $10 \mathrm{~min}$ at $4{ }^{\circ} \mathrm{C}$, and the supernatant containing the extracted 205 anthocyanins was collected. The extraction operation was repeated twice again with the 206 pellet and the final volume carried to $30 \mathrm{~mL}$. After the determination of the appropriate 207 dilution factor, two solutions of each test sample were prepared, one with $\mathrm{pH}=1.0$ aqueous 208 buffer (Potassium chloride, $0.025 \mathrm{M}$ ) and other with $4.5 \mathrm{pH}$ aqueous buffer (Sodium 209 acetate, $0.4 \mathrm{M}$ ). Total monomeric anthocyanin concentration was calculated measuring the 210 optical density at 520 and $700 \mathrm{~nm}$ at two different $\mathrm{pH}$ values $(\mathrm{pH}=1.0$ and 4.5). 211 Absorbance was measured within 20-50 min of preparation vs $\mathrm{MeOH}: \mathrm{HCl}(99: 1$, v/v) at $212 \mathrm{pH} 1$ and 4.5 using the same dilution factor. The calculation of monomeric anthocyanin 213 concentration, expressed as g cyanidin 3-O-glucoside equivalents per kg fresh weight, as 214 follows:

215

216 $T M A\left(\mathrm{~g} \mathrm{CGE} \mathrm{kg}{ }^{-1} \mathrm{FW}\right)=(A \times D F \times M W \times V \times \mathrm{DM}) /(\varepsilon \times W \times l \times 10)$

Where $A=\left(A_{520 n m}-A_{700}{ }_{n m}\right) \mathrm{pH}=1.0-\left(A_{520 n m}-A_{700} n m\right) \mathrm{pH}=4.5 ; D F=$ Dilution 219 factor; $M W$ (Molecular weight) $=449.2 \mathrm{~g}$ mol for cyanidin 3-O-glucoside; $V=$ total 220 extraction volume $(\mathrm{mL}) ; \mathrm{DM}=\mathrm{g}$ dry matter per $\mathrm{kg}$ fresh weight; $\varepsilon$ (Molar extinction 
221 coefficient $)=26,9001 \mathrm{~cm}^{-1} \mathrm{M}^{-1}$ in aqueous solution; $W=$ sample weight $(\mathrm{g}) ; l=$ pathlenght $222(\mathrm{~cm})$.

223

\section{Extraction and quantitative determination of total carotenoids (TC)}

225 Total carotenoids were extracted and quantified according to Lachman et al. ${ }^{29}$ with some 226 modifications. Total carotenoids were extracted from fresh sample (15 g) after cryogenic 227 grinding with $10 \mathrm{~mL}$ of chilled acetone. Borosilicate tubes with acetonic extracts were 228 covered with tinfoil to prevent light activity and stored 3 days at $4{ }^{\circ} \mathrm{C}$. After this period, the 229 borosilicate tubes were put in an ultrasound bath and sonicated for $20 \mathrm{~min}$ and centrifuged 230 at $7730 \mathrm{~g}$ for $10 \mathrm{~min}$ at $4{ }^{\circ} \mathrm{C}$. The supernatant was collected, $10 \mathrm{~mL}$ of cold acetone were 231 added to the pellet, the solid was re-suspended by shaking in a vortex for $1 \mathrm{~min}$ and the 232 mixture was centrifuged. The extraction process was repeated once again and the filtrates 233 were made up to $25 \mathrm{~mL}$. The absorbance was measured at $444 \mathrm{~nm}$ using acetone as blank 234 and the total carotenoid content was expressed as g lutein equivalents per $\mathrm{kg} \mathrm{FW}$ from the 235 equation:

236

237 $\mathrm{TC}\left(\mathrm{g} \mathrm{LE} \mathrm{kg}^{-1} \mathrm{FW}\right)=\left(A_{444} n \mathrm{x} V \times 15\right) /\left(0.259 \times W \times 10^{3}\right)$ Where $\mathrm{A}=\mathrm{A}_{444 \mathrm{~nm}} ; \mathrm{V}=$ total extraction volume $(\mathrm{mL}) ; \mathrm{W}=$ sample weight $(\mathrm{g})$.

243 Hydrophilic antioxidant capacity was analysed following two methods, ABTS (2,2'-azinobis(3-ethylbenzothiazoline-6-sulphonic acid) and DPPH (2,2-diphenylpicrylhydrazyl), 
245 according to Choong et al. ${ }^{30}$. These two indicator radicals were neutralized either by direct

246 reduction via electron transfers or by radical quenching via $\mathrm{H}$ atom transfer, respectively.

247 The ABTS assay measures the relative ability of antioxidants to scavenge the radical ABTS

248 generated in aqueous phase compared with a Trolox standard (vitamin E analogue). The

249 DPPH assay is based on the loss of absorption of radical DPPH when reduced by

250 antioxidants. Both methods are widely used to determine antioxidant capacity of fruits,

251 vegetables and beverages ${ }^{31}$. Fresh samples $(2.5 \mathrm{~g})$ were grinded in a mortar in liquid

252 nitrogen. Hydrophilic antioxidants were extracted with $10 \mathrm{~mL} \mathrm{MeOH:} \mathrm{H}_{2} \mathrm{O}(70: 30$, v/v).

253 The mixture was centrifuged at $7730 \mathrm{~g}$ for $10 \mathrm{~min}$ at $4{ }^{\circ} \mathrm{C}$, and the supernatant containing

254 the extracted antioxidant was collected. The solid was suspended by shaking in a vortex for

$2551 \mathrm{~min}$ and the extraction operation was repeated twice again with the pellet and the final

256 volume carried to $30 \mathrm{~mL}$. The $\mathrm{ABTS}^{\circ+}$ solution was prepared by mixing $8 \mathrm{mM}$ of ABTS

257 salt with $3 \mathrm{mM}$ of potassium persulfate in $25 \mathrm{~mL}$ of $\mathrm{DIH}_{2} \mathrm{O}$. The solution was held at room

258 temperature in the dark for $16 \mathrm{~h}$ before use. The $\mathrm{ABTS}^{\bullet+}$ solution was diluted with $\mathrm{MeOH}$ :

$259 \mathrm{H}_{2} \mathrm{O}(70: 30, \mathrm{v} / \mathrm{v})$ in order to obtain an absorbance between 0.8 and 0.9 at $734 \mathrm{~nm}$.

260 Antioxidant or standard solutions, $20 \mu \mathrm{L}$, were mixed with $980 \mu \mathrm{L}$ of diluted ABTS $^{\circ+}$

261 solution and incubated at room temperature. A reaction of $30 \mathrm{~min}$ was used for all the

262 ABTS assays. In the DPPH assay, aliquots of the hydrophilic extracts were diluted (1:10,

$263 \mathrm{v} / \mathrm{v})$ and $0.1 \mathrm{~mL}$ of the diluted sample was added to $3.9 \mathrm{~mL}$ of $\mathrm{DPPH}{ }^{\bullet} \mathrm{MeOH}: \mathrm{H}_{2} \mathrm{O}(70: 30$,

$264 \mathrm{v} / \mathrm{v})$ solution $\left(6 \times 10^{-5} \mathrm{~mol} \mathrm{~L}^{1}\right)$ to initiate the reaction. Absorbance was measured at $516 \mathrm{~nm}$.

265 A reaction of $3 \mathrm{~h}$ was used for all the DPPH assays. In both methods $\mathrm{MeOH}: \mathrm{H}_{2} \mathrm{O}(70: 30$,

$266 \mathrm{v} / \mathrm{v})$ was used as blank and trolox $\mathrm{MeOH}: \mathrm{H}_{2} \mathrm{O}(70: 30$, v/v) dilutions were used as standard

$267(0,100,200,300,400$ and $500 \mu \mathrm{M})$. The antioxidant activity was reported in mol trolox

268 equivalents per $\mathrm{kg}$ fresh weight. 


\section{Statistical analysis}

\section{$270 \quad$ ANOVA and correlation matrix}

271 One-way ANOVA was used to analyse the differences in the concentration of total 272 soluble phenolics, total monomeric anthocyanins, total carotenoids, hydrophilic antioxidant 273 capacity and vitamin $\mathrm{C}$ among coloured potato genotypes. A $p$ value $\leq 0.05$ was considered 274 to be significant. Correlation analyses between parameters were calculated by using the 275 CORR procedure of the SAS package ${ }^{32}$.

\section{$P L S-D A$}

279 Partial Least Squares Discriminant Analysis (PLS-DA) is a linear supervised classification 280 technique based on the PLS regression algorithm ${ }^{33}$. However, in PLS-DA a dummy 281 response matrix $\mathrm{Y}$ must be introduced to account for classification problems. This matrix 282 must be binary-coded $(0,1)$ with the same number of rows as $\mathrm{X}$ and same columns as 283 groups object of study ${ }^{34}$. PLS-DA explains the variability presented in the data by creating 284 linear combinations of the originals variables, called Latent Variables (LVs). The first LV 285 covers the most variation in the data while the second most of the remaining and so on ${ }^{35}$. 286 In this study, 3 PLS-DA models were performed to classify the varieties into three groups 287 according to their phytochemical concentration level and called: low content (LC), mid 288 content (MC) and high content (HC). The first PLS-DA model corresponded to varieties 289 grouped according to their content of total soluble phenolics (TSP), total monomeric 290 anthocyanins (TMA) and hydrophilic antioxidant capacity (HAC), since these three 291 appeared to be well correlated in this study. Correlation between these three 
292 phytochemicals was also found by other authors ${ }^{14}$. The second PLS-DA performed 293 comprised groups categorised by their total carotenoids (TC) content. Finally, a third PLS294 DA was accomplished covering varieties grouped by means of VC level.

295 Consequently, a 3-column response Y matrix was introduced for each PLS-DA in 296 which varieties defined as having low content of phytochemicals were described by the 297 dependent vector [ $\left[\begin{array}{lll}1 & 0 & 0\end{array}\right]$, varieties belonging to $\mathrm{MC}$ group, by the vector $\left[\begin{array}{lll}0 & 1 & 0\end{array}\right]$ and the 298 ones belonging to the HC group by the vector [ $\left[\begin{array}{lll}0 & 0 & 1\end{array}\right]$. Samples of the different varieties 299 were randomly divided into calibration and prediction sets corresponding to $70 \%$ and $30 \%$ 300 of samples respectively. Only the calibration data set was used to build the classification 301 model while the prediction data set was used to externally evaluate its capability to classify 302 new samples. Data were pre-processed by Multiplicative Scatter Correction (MSC) and 303 Mean centre (MnC). Pre-processing methods are commonly used to reduce or avoid the 304 influence of unwanted effects in the data that could negatively affect the consistency of the 305 model ${ }^{36-37}$. MSC reduces scatter effects in the data ${ }^{38}$ while MC reduces systematic noise $306 \quad 37$. The cross-validation (CV) method employed was Venetian Blinds with 10 data (splits) 307 subsets since this method is considered simple and easy to implement. In this study the 308 accuracy of the models was evaluated by the percentage of correctly classified samples in 309 each group in calibration (Cal), cross-validation (CV) and Prediction (Pred). Both pre310 processing of data and PLS-DA were performed in the PLS-Toolbox (Eigenvector 311 Research Inc, Wenatchee, USA) working under Matlab R2014a (The Mathworks, MS, 312 Natick, USA). 
314

315

316

317

318

319

320

321

322

323

324

325

326

327

328

329

330

331

332

333

334

335

336

337

\section{RESULTS}

\section{Chemical analysis}

The tested potato cultivars showed significant differences among each other in terms of total soluble phenolics (TSP), total monomeric anthocyanins (TMA), total carotenoids (TC) and vitamin $\mathrm{C}(\mathrm{VC})(p \leq 0.05)$, thus genotype greatly affected all measured phytochemicals (Table 2). TSP concentrations, ranging from $0.140 \pm 0.0208$ to $2.78 \pm 0.0512 \mathrm{~g} \mathrm{GAE} \mathrm{kg}^{-1}$ FW, were higher in the genotypes Violet Queen, Purple Peruvian and Highland Burgundy Red, while lowest TSP contents were found in NK-08/360, NK-08/349, NK-08/362 and Morea. TMA values ranged from $0.000100 \pm 0.0000100$ to $1.33 \pm 0.0111 \mathrm{~g} \mathrm{CGE} \mathrm{kg}^{-1} \mathrm{FW}$. Highest TMA concentrations were also measured in the cultivars Violet Queen, Purple Peruvian, Highland Burgundy Red and Vitelotte, while lowest TMA concentrations were found in NK-08/360, Kasta, Rosa Roter and Morea. There is a six-fold variation in TC values which ranged from $0.00915 \pm 0.00135$ to $0.0590 \pm 0.00425 \mathrm{~g} \mathrm{LE} \mathrm{kg}^{-1} \mathrm{FW}$. TC concentrations were higher in the cultivars Morada, Highland Burgundy Red, Rouge de Flandes and Rosa Roter, whereas Bleu de La Manche, Fenton and Blue Congo showed the lowest TC values. VC concentrations ranging from $0.0366 \pm 0.0149$ to $0.107 \pm 0.0204 \mathrm{~g} \mathrm{~kg}^{-}$

${ }^{1} \mathrm{FW}$ showed a three-fold variation among the collection of purple and red fleshed tubers. VC values were higher in Blue Congo, Morada and Kasta, while Rosa Roter, NK-08/349 and Highland Burgundy Red showed the lowest VC concentrations.

Statistical analyses revealed considerable differences in hydrophilic antioxidant capacity (HAC) between cultivars at $p \leq 0.05$ (fig. 4). The highest HAC value was measured in the cultivar Violet Queen $\left(\mathrm{HAC}_{\mathrm{ABTS}}=0.00939 \pm 0.000171 ; \mathrm{HAC}_{\mathrm{DPPH}}=\right.$ $\left.0.00944 \pm 0.0000656 \mathrm{~mol} \mathrm{TE} \mathrm{kg}{ }^{-1} \mathrm{FW}\right)$, while Morea showed the lowest HAC value 
338

339

340

341

342

343

344

345

346

347

348

349

350

351

352

353

354

355

356

357

358

359

360

$\left(\mathrm{HAC}_{\mathrm{ABTS}}=0.00420 \pm 0.000315 ; \mathrm{HAC}_{\mathrm{DPPH}}=0.00255 \pm 0.000136 \mathrm{~mol} \mathrm{TE} \mathrm{kg}{ }^{-1} \mathrm{FW}\right)$. The HAC measured in Violet Queen was between 125 and $270 \%$ higher than the HAC of the cultivar Morea, depending on the analytical method. The statistical analysis revealed very strong correlations $(p \leq 0.001)$ and correlation coefficients higher than 0.78 among the following pairs of variables: TSP - TMA, TSP - HAC.ABTS, TMA - HAC.DPPH, TSP HAC.DPPH and TMA - HAC-DPPH (Table 3). The highest $r$ value was found for the HAC measured by ABTS and DPPH assays $(r=0.91)$, while other pairs of variables, such as TC - HAC, VC - TSP, VC - TMA, VC - HAC and VC - TC, showed $r$ values close to 0.

\section{PLS-DA}

In this study, in order to perform a PLS-DA, once the phytochemical content of each variety was determined, samples were arbitrary divided into three groups according to the level of those compounds. As previously mentioned, 3 different PLS-DA models were performed.

\section{Total soluble phenolics (TSP), total monomeric anthocyanins (TMA) and hydrophilic} antioxidant capacity $(\mathrm{HAC})$ model

Fig. 1 shows the varieties included in each of the three groups in the first PLS-DA carried out. It should be mentioned that only 16 varieties were included in this model, excluding Kasta and Rosa Roter since those two did not show correlation between TSP, TMA and HAC values. Samples $(n=429)$ were randomly divided between calibration and validation sets $\left(\mathrm{n}_{\mathrm{cal}}=302, \mathrm{n}_{\mathrm{val}}=127\right)$. As it is shown in Fig 1 , LC group comprised 165 samples belonging to 6 categories defined as having less than $0.900 \mathrm{~g} \mathrm{GAE} \mathrm{kg}^{-1} \mathrm{FW}$ of TSP, $0.125 \mathrm{~g}$ 
$361 \mathrm{CGE} \mathrm{kg}^{-1} \mathrm{FW}$ of TMA and $0.00400 \mathrm{~mol} \mathrm{TE} \mathrm{kg}{ }^{-1} \mathrm{FW}$ of HAC. It should be noted that 362 variety NK-08/362 was included in this group only attending to their TSP and HAC 363 content, because if according to its TMA content, it must have been included in the second 364 group (MC).

The second group, MC, covered 132 samples belonging to 5 varieties with levels of 366 TSP, TMA and HAC of $0.900-1.20 \mathrm{~g} \mathrm{GAE} \mathrm{kg}^{-1} \mathrm{FW}, 0.125-0.240 \mathrm{~g} \mathrm{CGE} \mathrm{kg}^{-1} \mathrm{FW}$ and $0.00400-0.00600 \mathrm{~mol} \mathrm{TE} \mathrm{kg}{ }^{-1} \mathrm{FW}$ respectively. Lastly, HC group also contained 132 samples from 5 different varieties with levels above $1.20 \mathrm{~g} \mathrm{GAE} \mathrm{kg}^{-1} \mathrm{FW}, 0.240 \mathrm{~g} \mathrm{CGE} \mathrm{kg}^{-}$ ${ }^{1} \mathrm{FW}$ and $0.00600 \mathrm{~mol} \mathrm{TE} \mathrm{kg}^{-1} \mathrm{FW}$ of TSP, TMA and HAC respectively.

As revealed before, PLS-DA models were evaluated in terms of correctly classified 371 samples in each of the three groups (LC, MC and HC). In Table 4 the confusion matrix 372 obtained with the PLS-DA can be seen. It shows the percentage of correctly classified 373 samples of each of the 3 groups in calibration (Cal), cross-validation (CV) and prediction 374 (Pred). The diagonal of each confusion matrix represents the percentage of samples 375 correctly classified into the group they belong to while the values outside it correspond to 376 wrongly classified samples, into a different group. A perfect classification corresponds to a 377 matrix with a diagonal full of $100 \%$ surrounded by $0.00 \%$ rates.

In this study, a total of 9 LVs were used explaining $99.9 \%$ of the total variance.

Slightly better classification rates were obtained for the LC group than for the rest of the

380 groups. This was expected since samples into LC group presented values far away from the

381 other two groups that had more similar values between each other. In any case, good rates 382 above $80.0 \%$ of correctly classified samples were achieved for Cal and CV sets. However, 383 LC group was the best classified for the three Cal, CV and Pred sets with more than $90.0 \%$ 384 of samples correctly classified. It should be mentioned that the percentages of samples from 
385 LC group that were badly classified into the other two groups corresponded to Valfi and 386 NK-08/362 varieties, the ones with the highest values of phytochemicals inside this group.

387 Moreover, as mentioned before if only taking into account TMA content of samples, NK388 08/362 should be included in MC group, therefore, some misclassification of this variety 389 was expected.

390 Some misclassification was also found in MC group in which a few samples belonging 391 to Blue Star and Fenton varieties, with the lowest values of phytochemicals, were classified 392 into LC group. On the other hand, a few samples belonging to British Columbia Blue and 393 Blue Congo were identified as having HC. Finally, in HC group, a small number of 394 samples from Vitelotte and Rouge de Flandes were incorrectly classified into MC. In this 395 group, again, those varieties were the ones with the lowest values of phytochemicals of the 396 group.

397 The results obtained demonstrated that in this study, PLS-DA classification technique 398 enabled identification of different varieties of potato with low, mid and high content of 399 TSP, TMA and HAC.

$400 \quad$ Fig 5 is the graphical representation of the confusion matrix for each group included in 401 this study. The horizontal black line indicates the threshold above a sample is assigned to a 402 particular class. Therefore, in Fig 5 (a), all samples located above the threshold are 403 classified as belonging to LC group. It can be seen that there are a few samples belonging 404 to MC and HC groups that according to this plot were classified as LC. Similarly, all the 405 samples above the threshold in Fig 5 (b) and 5 (c) were classified as belonging to MC and $406 \mathrm{HC}$ respectively. In these plots, the prediction set of samples appeared inside a circle for the 407 sake of easier visualization. 
409

\section{Total carotenoids model}

410 Fig. 2 shows the varieties included in each of the three groups in the second PLS-DA. All 41118 varieties were included in this model. $70.0 \%$ of the total number of samples $(n=471)$ 412 were randomly selected for the calibration set $\left(\mathrm{n}_{\mathrm{cal}}=315\right)$ and $30.0 \%$ for validation $\left(\mathrm{n}_{\mathrm{val}}=\right.$ 413 156). As it is observed in Fig. 2, LC group comprised 192 samples belonging to 7 414 categories with TC content below $0.0200 \mathrm{~g} \mathrm{LE} \mathrm{kg}^{-1} \mathrm{FW}$, while the second group (MC) has 415 a total of 132 samples from to 5 varieties with TC values between 0.0200 and $0.0300 \mathrm{~g}$ LE $416 \mathrm{~kg}^{-1} \mathrm{FW}$, lastly, HC group is formed by 147 samples from 6 different varieties with TC 417 levels above $0.0300 \mathrm{~g} \mathrm{LE} \mathrm{kg}^{-1} \mathrm{FW}$.

418 A total of $8 \mathrm{LVs}$ were selected in this PLS-DA model explaining the $99.96 \%$ of 419 variance. Table 5 shows the percentage of correctly classified samples into the three 420 groups. It is observed that it was not possible to obtain an accurate classification of both LC 421 and MC groups since a small number of samples were correctly classified into the group 422 they belonged to and the fact that a considerable percentage of samples were classified in 423 either of the other two groups. Thus, $17.2 \%$ and $31.2 \%$ of samples belonging to LC were 424 classified as $\mathrm{MC}$ and $\mathrm{HC}$ respectively while $39.1 \%$ and $30.43 \%$ of samples of MC group 425 were classified as LC and $\mathrm{HC}$ respectively in the Pred set. On the other hand, a high 426 percentage of correctly classified samples was achieved in the HC group of around $80 \%$. 427 These results, suggests that NIRS technology could be used for screening processes in order 428 to identified samples with high content of TC.

429

430

\section{Vitamin C model}

431 In Fig. 3 the varieties included in each of the three groups in the third PLS-DA are shown. 432 Once again, samples $(n=471)$ were randomly divided between calibration and validation 
433 sets $\left(\mathrm{n}_{\mathrm{cal}}=315, \mathrm{n}_{\mathrm{val}}=156\right)$. In this analysis, $\mathrm{LC}$ group comprised 174 samples belonging to 7 434 categories defined as having less than $0.0700 \mathrm{~g} \mathrm{~kg}^{-1} \mathrm{FW}$ of $\mathrm{VC}$, the second group, $\mathrm{MC}$, 435 covered 162 samples belonging to 6 varieties with VC content between 0.0700 and 0.0920 $436 \mathrm{~g} \mathrm{~kg}^{-1} \mathrm{FW}$ and finally, HC group contained 135 samples from 5 different varieties with 437 levels above $0.0920 \mathrm{~g} \mathrm{~kg}^{-1} \mathrm{FW}$.

438 A total of 5 LVs were selected explaining the $99.8 \%$ of the variance. Low classification 439 rates, below 63.0\%, were obtained for this PLS-DA (data not shown) for Cal, CV and Pred 440 sets. Besides, high misclassification was found between LC and HC groups. Around 30.0\% 441 of samples belonging to $\mathrm{HC}$ group were wrongly classified as LC in Cal, CV and Pred sets 442 suggesting that results were not reliable. It is worth mentioning that vitamin $\mathrm{C}$ content in 443 potatoes highly depends on many factors and can vary considerably from one campaign to 444 another. Thus, it becomes very challenging to perform robust classification methods for this 445 compound. Moreover, significantly lower contents of VC were found in this study 446 compared to other authors as mentioned before, due to the effect of cold temperatures 447 during storage. Therefore, we consider that these facts could be responsible for the low 448 classification rates obtained in this work.

\section{DISCUSSION}

451

\section{Phytochemical quantification}

453 In the present study, the vitamin $\mathrm{C}$ concentrations were significantly lower than those 454 reported by authors as Love et al. ${ }^{39}$ or Han et al. ${ }^{40}$, who found concentration values 455 ranging from 0.115 to $0.420 \mathrm{~g} \mathrm{~kg}^{-1} \mathrm{FW}$ in white or yellow fleshed commercial cultivars and 456 breeding lines from North America. Similar to our data, Jimenez et al. ${ }^{41}$ reported lower 
457 vitamin $\mathrm{C}$ concentrations ranging from 0.0754 to $0.286 \mathrm{~g} \mathrm{~kg}^{-1} \mathrm{FW}$ in a collection of seven 458 Andean potato cultivars. According to the CD 2008/100/EC ${ }^{42}$, an average edible portion 459 (100 g of peeled tubers) contains about 4.6 to $13.3 \%$ of the recommended daily intake 460 (RDA) of vitamin C. Moreover, considering the high losses during thermal processing from $46125 \%$ to $40 \%{ }^{43-44}$ these cultivars should be considered only as a relatively poor source of 462 vitamin C. However, numerous studies have shown that vitamin C levels are highly 463 dependent on many factors, such as culture conditions, wounding and storage, which can 464 alter rapidly it concentration in tubers ${ }^{45-46}$. According to Oba et al. ${ }^{47}$ the vitamin C 465 contents in potato tubers stored at $4{ }^{\circ} \mathrm{C}$ for one month may experience a decrease from 46 466 to $57 \%$. Thus, the effect of cold storage on vitamin C could explain why our values were 467 significantly lower than those reported by other authors.

468 TSP values showed wide variability among the collection of purple or red fleshed 469 cultivars or breeding lines showing the great genotype effect on these phytochemicals. This 470 is about a 20 -fold variation in total soluble phenolics and the highest TSP values are 471 generally comparable to those of blueberries (Vaccinium corymbosum L.) ${ }^{48-49}$. 472 Accordingly, a study of 74 Andean potato landraces found about an 11-fold variation in 473 TSP values ${ }^{10}$. Despite the fact that published data vary widely, those measured by Folin 474 Ciocalteau method usually show lower value range from 0.0200 to $1.00 \mathrm{~g} \mathrm{GAE} \mathrm{kg}^{-1} \mathrm{FW}^{50-}$ $475{ }^{52}$ due to the limits of the method compared to the Fast Blue method used in this study ${ }^{53}$. 476 Our results are in agreement with previous works reporting higher TSP values in coloured 477 potato tubers, for instance, ${ }^{54}$ found TSP levels about 0.250 and $2.87 \mathrm{~g} \mathrm{GAE} \mathrm{kg}^{-1} \mathrm{FW}$, while 478 Stushnoff et al. ${ }^{55}$ reported values between 0.900 and $4.00 \mathrm{~g} \mathrm{GAE} \mathrm{kg}^{-1} \mathrm{FW}$ in a collection of 479 coloured accessions. 
Total monomeric anthocyanins (TMA) values found in the present tubers (from 0.000100 to $1.33 \mathrm{~g} \mathrm{CGE} \mathrm{kg}^{-1} \mathrm{FW}$ ) were similar to almost published total monomeric anthocyanin values in purple or red potato tubers. Reyes et al. ${ }^{14}$ found TMA values between 0.210 and $0.550 \mathrm{~g} \mathrm{CGE} \mathrm{kg}^{-1} \mathrm{FW}$ in red fleshed tubers, and between 0.110 and 1.75 g CGE kg ${ }^{-1} \mathrm{FW}$ in purple fleshed ones. In fact, $1.75 \mathrm{~g} \mathrm{CGE} \mathrm{kg}^{-1} \mathrm{FW}$ is an extremely high value for potato which has not been equalled in consulted bibliography. In this respect, it should be noted that potato peels contain higher anthocyanin levels and the evaluation of coloured cultivars and breeding lines by Reyes et al. ${ }^{14}$ was performed using unpeeled tubers. Brown et al. ${ }^{56}$ reported TMA values between 0.150 and $0.400 \mathrm{~g} \mathrm{CGE} \mathrm{kg}^{-1} \mathrm{FW}$ in 18 pigmented clones and cultivars. Jansen and Flamme ${ }^{57}$ also found TMA contents ranging from 0 to $0.800 \mathrm{~g} \mathrm{CGE} \mathrm{kg}^{-1} \mathrm{FW}$ in 31 potato accessions. These highest values are nearly 2.8 and 1.5 times less than the TMA content of Violet Queen in each case. TMA content value of Violet Queen is comparable to that of Vaccinum L. berries, which are considered to be a one of the richest natural sources of anthocyanins with TMA contents ranging from 1.38 to $3.85 \mathrm{~g} \mathrm{CGE} \mathrm{kg}^{-1} \mathrm{FW}^{58}$. However, the daily intake of potatoes usually is much higher than the daily intake of blueberries 59 .

TMA values were well correlated with TSP and hydrophilic antioxidant capacity. The correlation between antioxidant capacity and phenolics has also been reported ${ }^{8,15}$. Present values of hydrophilic antioxidant capacity were higher than that of white or yellow fleshed potatoes ${ }^{58}$, but our values are similar to those obtained by Brown et al. ${ }^{56}$ in coloured potato breeding lines. In relation to the total carotenoid concentrations, values ranging from 0.00910 to $0.0588 \mathrm{~g} \mathrm{LE} \mathrm{kg}^{-1} \mathrm{FW}$ are comparable to those obtained by Lachman et al. ${ }^{29}$ using the same colorimetric method $\left(0.000200-0.0250 \mathrm{~g} \mathrm{LE} \mathrm{kg}^{-1} \mathrm{FW}\right)$. The lipophilic character of most carotenoids can explain the lack of correlation between TC and HAC. 
504 With the exception of Violet Queen, higher TC values were detected in tubers with a 505 perceptible partially yellow coloration, such as Morada, Rosa Roter, Rouge de Flandes and 506 Highland Burgundy Red. Relatively low TC values were found in most of the medium or 507 deep purple cultivars. According to Kotíková et al. ${ }^{61}$, deep purple potato cultivars generally 508 have lower ability to synthesize and accumulate carotenoids when compared to yellow 509 fleshed potato cultivars.

510 According to several authors, purple and red fleshed genotypes are a great source of 511 certain minerals, phenolic compounds and antioxidant capacity. We have identified 512 cultivars and breeding lines with very high concentrations of carotenoids (Morada, 513 Highland Burgundy Red and Violet Queen), vitamin C (Blue Congo, Morada and Kasta), 514 soluble phenolics, monomeric anthocyanins and hydrophilic antioxidant capacity (Violet 515 Queen, Purple Peruvian and Vitelotte). Besides the commercial, gastronomical and medical 516 importance of quality parameters in coloured tubers, the identification of phytochemical 517 high producing germplasm is a key step to develop a potato breeding program for 518 nutritional quality.

520 Sample classification by NIR spectroscopy

521 Some authors have studied the non-destructive determination of some chemical compounds 522 in potatoes. Thus, polyphenols content of lyophilized potatoes was accurately predicted by 523 using Fourier transform infrared spectroscopy achieving correlation values of $0.99^{62}$. 524 Moreover, other authors obtained good correlation coefficients when estimating the total 525 and individual carotenoid concentration in potatoes by NIR spectroscopy ${ }^{63}$.

526 As explained before, there is a little literature concerning qualitative analysis of 527 potatoes by NIR spectroscopy despite its potential. Even so, some authors successfully 
528 investigated the discrimination of two categories of potato samples regarding their 529 recoverable protein content. An overall $87.5 \%$ of correctly classified samples was achieved 530 in that study ${ }^{23}$. Other authors were able to classify potato chips by source of frying oil by 531 combining NIR spectroscopy and Soft Independent Modeling of Class Analogy (SIMCA) $532 \quad 64$

533 In this study we have successfully classified samples into three levels according to 534 their content of TSP, TMA and HAC. Figure $5(\mathrm{a}, \mathrm{b} \& \mathrm{c})$ confirms the results obtained, as it 535 shows that the majority of the samples of each group are correctly classified into them. 536 However, there was some misclassification as previously described, but we can say that 537 overall, very good rates of discrimination were obtained.

538 Therefore, we can say that according to this study, NIR spectroscopy combined with 539 PLS-DA was capable of accurately identifying samples containing different levels of TSP, 540 TMA and HAC belonging to this collection of 18 purple and red-fleshed potatoes.

541 Regarding TC content, we found that NIRs technique was only capable of identifying 542 samples with high content of this compound among the varieties analysed. Information that 543 could be useful for screening processes.

544 Finally, the classification results achieved according to the content of Vitamin C 545 suggested that it was not possible to obtained a reliable classification of varieties regarding 546 their VC content by NIRS technology.

547 Nevertheless, these findings are of great importance considering the continuously 548 increasing demand for quality control of food products among consumers and authorities ${ }^{65}$. 549 The outcome from this study could be considered as a screening step for future potato 550 breeding programs. Further research is advisable including a larger set of samples 551 comprising not only coloured varieties but yellow skin tuber as well. 


\section{CONCLUSION}

553

554 The identification of potato genotypes high in phenolic compounds, carotenoids and 555 antioxidant capacity is a key step for both identifying phytochemical rich food products and 556 for developing breeding lines with high concentrations of bioactive compounds. The 557 automatic and non-destructive characterization of cultivars and breeding lines with different 558 levels of bioactive compounds through near-infrared spectroscopy can be also suitable for 559 discriminating and classifying potato tubers in terms of phytochemical content.

560

561 ACKNOWLEDGMENTS

562 This work was financed within the frame of INIA's project RTA2013-00006-C03 and the 563 Basque Government.

564

565

566

5671 Navarre DA, Goyer A and Shakya R, Nutritional value of potatoes: Vitamin, 568 phytonutrient, and mineral content. In: Advances in potato chemistry and technology, 569 Singh J. and L. Kaur. (Eds.). Oxford, UK: Elsevier Publication. pp 395-424 (2009).

5702 Storey M, The Harvested Crop: Nutritional Value. In: Potato biology and biotechnology. 571 Advances and perspectives. Vreugdenhil D, J Bradshaw, CH Gebhardt, F Govers, DKL 572 Mackerron, MA Taylos, and HA Ross (Eds.) Oxford, UK: Elsevier Publication. pp $573 \quad 442-443(2007)$.

5743 Grosso G, Bei R, Mistretta A, Marventano S, Calabrese G, Masuelli L, Giganti MG, 575 Modesti A, Galvano F and Gazzolo D, Effects of vitamin C on health: a review of $576 \quad$ evidence. Frontiers Biosci 18: 1017-1029 (2013). 
5774 Rice-Evans CA, Miller JM and Paganga G, Structure-antioxidant activity relationship of $578 \quad$ flavonoids and phenolic acids. Free Rad Bio Med. 20, 933-956 (1996).

5795 Brown CR. 2005. Antioxidants in potato. Am J Pot Res 82: 163-172.

5806 Kita A, Bąkowska-Barczak A, Hamouz K, Kułakowska K and Lisińska G, The effect of 581 frying on anthocyanin stability and antioxidant activity of crisps from red- and purple582 fleshed potatoes (Solanum tuberosum L.). J Food Compos Anal 32: 169-175 (2013).

5837 Marko D, Puppel N, Tjaden Z, Jakobs S and Pahlke G, The substitution pattern of 584 anthocyanidins affects different cellular signaling cascades regulating cell $585 \quad$ proliferation. Mol Nutr Food Res 48: 318-325 (2004).

5868 Andre CM, Ghislain M, Bertin P, Oufir M, Herrera MR, Hoffmann L, Hausman JF, 587 Larondelle Y and Evers D, Andean potato cultivars (Solanum tuberosum L.) as a $588 \quad$ source of antioxidant and mineral micronutrients. $J$ Agric Food Chem 55: 366-378 $589 \quad$ (2007).

5909 Rodriguez-Amaya DB and Kimura M, HarvestPlus Handbook for carotenoid analysis. 591 HarvestPlus Technical Monograph 2. Washington, DC and Cali. International Food 592 Policy Research Institute (IFPRI) and International Center for Tropical Agriculture $593 \quad$ (CIAT) (2004).

59410 Rao AV and Rao LG, Carotenoids and human health. Pharm Res 55: 207-216 (2007).

$59511 \mathrm{Lu}$ W, Haynes K, Wiley E and Clevidence B, Carotenoid content and color in diploid 596 potatoes. J Am Soc Hort Sci 126: 722-726 (2001).

59712 Griffiths W, Dale F, Morris W and Ramsay G, Effects of season and postharveststorage 598 on the carotenoid content of Solanum phureja potato tubers. J Agric Food Chem 55, $599 \quad 379-385(2007)$. 
60013 Burgos G, Salas E, Amorós W, Auqui M, Muñoa L, Kimura M and Bonierbale M, 601 Total and individual carotenoid profiles in Solanum phureja of cultivated potatoes: I. 602 Concentrations and relationships as determined by spectrophotometry and HPLC. J $603 \quad$ Food Compos Anal 22: 503-508 (2009).

60414 Reyes LF, Miller JC and Cisneros-Zevallos L, Antioxidant capacity, anthocyanins and 605 total phenolics in purple- and red-flesh potato (Solanum tuberosum L.) genotypes. $606 \quad$ Am J Pot Res 82: 271-277 (2005).

60715 Hamouz K, Lachman J, Dvořák P, Jůzl M and Pivec V, The effect of site conditions, 608 variety and fertilization on the content of polyphenols in potato tubers. Plant, Soil \& $609 \quad$ Env 52: 407-412 (2006).

61016 Chen JY, Zhang H, Yelian M and Asakura M, Nondestructive determination of sugar 611 content in potato tubers using visible and near infrared spectroscopy. JPN J Food Eng 612 11: 59-64 (2010).

61317 Magwaza LS, Opara UL, Nieuwoudt H, Cronje PJR, Saeys W and Nicolaï B, NIR 614 spectroscopy applications for internal and external quality analysis of citrus fruit- A 615 Review. Food Bioprocess Tech 5: 425-444 (2012).

61618 Gunasekaran S and Irudayaraj J, Nondestructive Food Evaluation. Techniques to 617 analyse properties and quality, optical methods: visible NIR and FTIR spectroscopy. $618 \quad$ New York: Marcel Dekker (2000).

61919 Nicolaï BM, Beullens K, Bobelyn E, Peirs A, Saeys W, Theron KI and Lammertyn J, 620 Nondestructive measurement of fruit and vegetable quality by means of NIR 621 spectroscopy: A review. Postharvest Biol Tech 46: 99-118 (2007). 
62220 Lister SJ, Dhanoa MS, Stewart JL and Gill M, Classification and comparison of $<\mathrm{i}>$ 623 Gliricidia $</ \mathrm{i}>$ provenances using near infrared reflectance spectroscopy. Anim Feed 624 Sci Tech 86: 221-238 (2000).

62521 López A, Jarén C, Arazuri S, Mangado J, Tierno R, Ruiz de Galarreta JI and Riga P, 626 Estimation of the total phenolic content in potatoes by NIRS. In: International 627 Conference of Agricultural Engineering (Zurich, Switzerland), P0640 (2014).

62822 López A, Arazuri S, Jarén C, Tierno R, Ruiz de Galarreta JI and Riga P, Ability of 629 NIRS to estimate total phenolic content of lyophilized potatoes. In: Nústez, C.E.L., 630 L.E.M. Rodríguez, and TV. Mosquera (Eds.) XXVI Congreso Latinoamericano de la 631 papa - ALAP (Bogotá, Colombia), Calidad Nutricional, 105 (2014).

63223 Fernández-Ahumada E, Garrido-Varo A, Guerrero-Ginel JE, Wubbels A, Van der Sluis $633 \mathrm{C}$ and Van der Meer JM, Understanding factors affecting near infrared analysis of 634 potato constituents. J Near Infrared Spec 14: 27-35 (2006).

63524 Lammertyn JPA, De Baerdemaeker J and Nicolaï B, Light penetration properties of NIR 636 radiation in fruit with respect to non-destructive quality assessment. Meas Sci Technol 637 18: $121-32(2000)$.

63825 López A, Arazuri S, Mangado J, Jarén C and Ruiz de Galarreta JI, Determinación de la 639 penetración NIR en patata. VII Congreso Ibérico de Agroingeniería y Ciencias Hortícolas; 640 Madrid (España): Fundación General de la Universidad Politécnica de Madrid (2013).

64126 CAMAG, Vitamin C in fruit juice (Quantitative determinations). CAMAG Application 642 Note A-10.5, CAMAG, Muttenz, Switzerland. Home page: 643 http://www.camag.com/en/tlc_hptlc/camag_laboratory/methods.cfm, accessed January 644 2014. CAMAG, Application Notes (2012). 
64527 Medina MB, Simple and rapid method for the analysis of phenolic compounds in 646 beverages and grains. J Agric Food Chem 59: 1565-1571 (2011).

64728 Giusti M and Wrolstad RE, Current protocols in food analytical chemistry, in Current 648 Protocols in Food Analytical Chemistry, I. John Wiley and Sons, Editor. John Wiley 649 and Sons, Inc (2001).

65029 Lachman J, Hamouz K, Hejtmánková A, Dudjak J, Orsák M and Pivec V, Effect of 651 white fleece on the selected quality parameters of early potato (Solanum tuberosum L.) 652 tubers. Plant, Soil \& Env 49: 370-377 (2003).

65330 Choong CT, Van-Den TA, Roger A, McFeeters F, Roger L, Thompson KV, Pecota G 654 and Craig Y, Antioxidant activities, phenolic and $\beta$-carotene contents of sweet potato 655 genotypes with varying flesh colours. Food Chem 103: 829-838 (2007).

65631 Floegel A, Kim DO, Chung SJ, Koo SI and Chun OK, Comparison of ABTS/DPPH 657 assays to measure antioxidant capacity in popular antioxidant-rich US foods. J Food $658 \quad$ Compos Anal 24: 1043-1048 (2011).

65932 SAS, SAS/STAT 9.3. User'Guides Survey Datas Analysis. SAS Institute Inc, Cary, $660 \quad$ North Carolina, USA (2011).

66133 Ballabio D and Consonni V, Classification tools in chemistry. Part 1: linear models. 662 PLS-DA. Anal Methods 5: 3790-3798 (2013).

66334 Vitale R, Bevilacqua M, Bucci R, Magrì AD, Magrì SL and Marini F, A rapid and non664 invasive method for authenticating the origin of pistachio samples by NIR 665 spectroscopy and chemometrics. Chemometr Intell Lab 121: 90-99 (2013).

66635 Barker M and Rayens W, Partial least squares for discrimination. J Chemometr 17: 166$667 \quad 173(2003)$. 
66836 Amigo JM, Practical issues of hyperspectral imaging analysis of solid dosage forms. 669 Anal Bioanal Chem 398: 93-109 (2010).

67037 Barbin DF, ElMasry G, Sun DW and Allen P, Predicting quality and sensory attributes 671 of pork using near-infrared hyperspectral imaging. Anal Chim Acta 719: 30-42 (2012).

67238 Rinnan Å, Van den Berg F and Engelsen SB, Review of the most common pre673 processing techniques for near-infrared spectra. TrAC Trends Anal Chem 28: 1201$6741222(2009)$.

67539 Love SLST, Shafii B, Price WJ, Mosley AR and Thornton RE, Stability of expression 676 and concentration of ascorbic acid in North American potato germplasm. Hort Sci. 39: $677 \quad 156-160(2004)$.

67840 Han J, Kozukue N, Young K, Lee K and Friedman M, Distribution of ascorbic acid in 679 potato tubers and in home-processed and commercial potato foods. J Agric Food Chem $680 \quad$ 52: $6516-6521(2004)$.

68141 Jimenez ME, Rossi AM and Samman NC, Phenotypic, agronomic and nutritional 682 characteristics of seven varieties of Andean potatoes. J Food Compos Anal 22: 613$683 \quad 616(2009)$.

68442 CEC, CD 2008/100/EC of 28 October 2008 amending Council Directive 90/496/EEC on 685 nutrition labelling for foodstuffs as regards recommended daily allowances, energy 686 conversion factors and definitions. Official Journal of the European Union 285: 9-12. 687 Home

688 page:http://eurex.europa.eu/LexUriServ/LexUriServ.do?uri=OJ:L:2008:285:0009:0012 689 :EN:PDF, accessed June 2014. CEC, Commission of the European Communities $690 \quad$ (2008). 
69143 Hagg M., Hakkinen U, Kumpulainen J, Ahvenainen R and Hurme E, Effects of 692 preparation procedures, packaging and storage on nutrient retention in peeled potatoes. $693 \quad$ J Sci Food Agric 77: 519-526 (1998).

69444 Vanderslice JT, Higgs DJ, Hayes JM and Block G, Ascorbic acid and dehydroascorbic 695 acid content of foods-aseaten. J Food Compos Anal 3: 105-118 (1990).

69645 Tudela JA, Espín JC and Gil MI, Vitamin C retention in fresh-cut potatoes. Postharvest 697 Biol Tech 26: 75-84 (2002).

69846 Dale MFB, Griffiths DW and Todd DT, Effects of genotype, environment, and 699 postharvest storage on the total ascorbate content of potato (Solanum tuberosum L.) $700 \quad$ tubers. J Agric Food Chem 51: 244-248 (2003).

70147 Oba K, Yamamoto A, Ohara A, Ishii G and Omemura Y, Effect of storage temperature 702 on vitamin C levels and L-galactonolactone dehydrogenase activity of potato tubers. $J$ 703 Jpn Soc Food Sci Technol 45: 510-513 (2010).

70448 Zheng W and Wang SY, Oxygen radical absorbing capacity of phenolics in blueberries, 705 cranberries, chokeberries, and lingonberries. J Agric Food Chem 51: 502-509 (2002).

70649 You Q, Wang B, Chen F, Huang Z, Wang X and Luo PG, Comparison of anthocyanins 707 and phenolics in organically and conventionally grown blueberries in selected 708 cultivars. Food Chem 125: 201-208 (2010).

$70950 \mathrm{Hu} \mathrm{C}$, Tsao R, Liu R, Sullivan JA and McDonald MR, Influence of cultivar and year on 710 phytochemical and antioxidant activity of potato (Solanum tuberosum L.) in Ontario. $711 \quad$ Can J Plant Sci 92: 485-493 (2012).

71251 Aziz A, Yasin M, Randhawa MA, Yasmin A, Yahangir MA and Sohail M, Nutritional 713 and antioxidant profile of some selected Pakistani potato cultivars. Pak J Food Sci 23: $714 \quad 87-93(2013)$. 
71552 Murniece I, Kruma Z, Skrabule I and Vaivode A, Carotenoids and Phenols of 716 Organically and Conventionally Cultivated Potato Varieties. IJCEA 5: 342-348 (2013).

71753 Lester GE, Lewers KS, Medina MB and Saftner RA, Comparative analysis of 718 strawberry total phenolics via Fast Blue BB vs. Folin-Ciocalteu: Assay interference by 719 ascorbic acid. J Food Compos Anal 27: 102-107 (2012).

72054 Madiwale G, Effect of genotype, storage and processing on the polyphenolic content, 721 composition, in vitro anti-cancer activity and sensory attributes of colored-flesh 722 potatoes (PhD Thesis). Colorado State University, Fort Collins, Colorado (2012).

72355 Stushnoff C, Holm D, Thompson M, Jiang W, Thompson H, Joyce N and Wilson P, 724 Antioxidant properties of cultivars and selections from the Colorado Potato Breeding 725 Program. Am J Pot Res 85: 267-276 (2008).

72656 Brown CR, Culley D, Yang CP, Durst R and Wrolstad R, Variation of anthocyanin and 727 carotenoid contents and associated antioxidant values in potato breeding lines. $J$ Amer 728 Soc Hort Sci 130: 174-180 (2005).

72957 Jansen G and Flamme W, Coloured potatoes (Solanum Tuberosum L.) - anthocyanin $730 \quad$ content and tuber quality. Gen Res Crop Evol 53: 1321-1331 (2006).

73158 Cevallos-Casals BA and Cisneros-Zevallos L, Stoichiometric and kinetic studies of 732 phenolic antioxidants from Andean purple corn and red-fleshed sweetpotato. J Agric $733 \quad$ Food Chem 51: 3313-3319 (2003).

73459 FAO, FAOSTAT database. Home page: http://faostat.fao.org. FAO, Food and 735 Agriculture Organization of the United Nations (2012).

$73660 \mathrm{Wu}$ X, Beecher GR, Holden JM, Haytowitz DB, Gebhardt SE and Prior RL, Lipophilic 737 and Hydrophilic Antioxidant Capacities of Common Foods in the United States. J. $738 \quad$ Agric Food Chem 52: 4026-4037 (2004). 
73961 Kotíková Z, Hejtmánková A, Lachman J, Hamouz K, Trnková E and Dvorak P, Effect 740 of selected factors on total carotenoid content in potato tubers (Solanum tuberosum L.). $741 \quad$ Plant Soil \& Env 53: 355 (2007).

74262 Shiroma-Kian C, Tay D, Manrique L, Giusti MM and Rodriguez-Saona L, Improving 743 the screening process for the selection of potato breeding lines with enhanced 744 polyphenolics content. J Agr Food Chem 56: 9835-9842 (2008).

74563 Bonierbale M, Grüneberg W, Amoros W, Burgos G, Salas E, Porras E and Zum Felde. 746 T, Total and individual carotenoid profiles in Solanum phureja cultivated potatoes: II. 747 Development and application of near-infrared reflectance spectroscopy (NIRS) 748 calibrations for germplasm characterization. J Food Comp Anal 22: 509-516 (2009).

74964 Shiroma C and Rodriguez-Saona L, Application of NIR and MIR spectroscopy in 750 quality control of potato chips. J Food Comp Anal 22: 596-605 (2009).

75165 López A, Arazuri S, García I, Mangado J and Jarén C, A review of the application of 752 near-infrared spectroscopy for the analysis of potatoes. J Agr Food Chem 61: 5413$753 \quad 5424(2013)$.

754

755

756

757

758

759

760 
761 Figure captions:

762 Figure 1. Flowchart of varieties distribution according to their content of total soluble 763 phenolics (TSP), total monomeric anthocyanins (TMA) and hydrophilic antioxidant 764 capacity (HAC).

765 Figure 2. Flowchart of varieties distribution according to their content of total carotenoids 766 (TC).

767 Figure 3. Flowchart of varieties distribution according to their content of vitamin C (VC).

768 Figure 4. Hydrophilic antioxidant capacity (HAC) measured by ABTS and DPPH methods.

769 Means and standard deviations are expressed as mol trolox equivalents per $\mathrm{kg}$ FW. Average 770 values $(n=3)$ in columns labeled with the same letter are not significantly different at $p \geq$ $7710.05\left(\mathrm{LSD}_{\mathrm{ABTS}}=0.000474 ; \mathrm{LSD}_{\mathrm{DPPH}}=0.000240\right)$.

772 Figure 5. PLS-DA analysis of LC group (a), MC (b) and HC (c). Horizontal line (----) 773 indicates the threshold above a sample is assigned to a particular group.

774 
775 Table 1. Collection of 18 purple and red fleshed potato (Solanum tuberosum L.)

$776 \quad$ cultivars or breeding lines.

\begin{tabular}{llll}
\hline Cultivar or breeding lines & Origin & Status & Skin/Flesh type \\
\hline Bleu de La Manche & France & Cultivar & $\mathrm{P} / \mathrm{P}$ \\
Blue Congo & Sweden-UK & Cultivar & $\mathrm{P} / \mathrm{P}$ \\
Blue Star & Netherlands & Cultivar & $\mathrm{P} / \mathrm{P}$ \\
British Columbia Blue & Canada-UK & Cultivar & $\mathrm{P} / \mathrm{P}$ \\
Fenton & Canada-UK & Cultivar & $\mathrm{P} / \mathrm{P}$ \\
Highland Burgundy Red & France & Cultivar & $\mathrm{R} / \mathrm{R}$ \\
Kasta & Spain & Cultivar & $\mathrm{P} / \mathrm{P}$ \\
Morada & Spain & Cultivar & $\mathrm{P} / \mathrm{P}$ \\
Morea & Spain & Cultivar & $\mathrm{P} / \mathrm{P}$ \\
NK-08/349 & Spain & Breeding line & $\mathrm{P} / \mathrm{P}$ \\
NK-08/360 & Spain & Breeding line & $\mathrm{P} / \mathrm{P}$ \\
NK-08/362 & Spain & Breeding line & $\mathrm{P} / \mathrm{P}$ \\
Purple Peruvian & Peru & Cultivar & $\mathrm{P} / \mathrm{P}$ \\
Rosa Roter & Peru & Cultivar & $\mathrm{R} / \mathrm{R}$ \\
Rouge de Flandes & Belgium & Cultivar & $\mathrm{R} / \mathrm{R}$ \\
Valfi & Sweden-UK & Cultivar & $\mathrm{P} / \mathrm{P}$ \\
Violet Queen & Netherlands & Cultivar & $\mathrm{P} / \mathrm{P}$ \\
Vitelotte & France & Cultivar & $\mathrm{P} / \mathrm{P}$ \\
\hline & & trKey & \\
\hline
\end{tabular}

777

${ }^{1}$ Key to skin and tuber flesh types: $\mathrm{R}=$ Red, $\mathrm{P}=$ Purple.

778 
779 Table 2. Total soluble phenolics (TSP), total monomeric anthocyanins (TMA), total 780 carotenoids (TC) and vitamin C (VC) in peeled tubers of 18 purple and red fleshed potato 781 cultivars and breeding lines. Means and standard deviations of 1) TSP are expressed as $g$ 782 gallic acid equivalents per $\mathrm{kg}$ fresh weight; 2) TMA are expressed as g cyanidin 3783 glucoside equivalents per kg fresh weight; 3) TC are expressed as g lutein equivalents per $784 \mathrm{~kg}$ fresh weight; 4) VC are expressed as g of vitamin C per $\mathrm{kg}$ fresh weight $(\mathrm{n}=3)$.

785

\section{Cultivar/}

\begin{tabular}{|c|c|c|c|c|}
\hline Breeding line & TSP & TMA & TC & $\mathbf{V C}$ \\
\hline Bleu de La Manche & $0.915 \pm 0.0159$ & $0.230 \pm 0.0264$ & $0.00915 \pm 0.00135$ & $0.0831 \pm 0.00945$ \\
\hline Blue Congo & $1.18 \pm 0.0476$ & $0.178 \pm 0.0235$ & $0.00962 \pm 0.00125$ & $0.107 \pm 0.0204$ \\
\hline Blue Star & $1.08 \pm 0.0117$ & $0.129 \pm 0.0143$ & $0.0193 \pm 0.000700$ & $0.0907 \pm 0.00361$ \\
\hline British Columbia Blue & $1.12 \pm 0.0833$ & $0.228 \pm 0.0316$ & $0.0161 \pm 0.00200$ & $0.0577 \pm 0.00971$ \\
\hline Fenton & $1.00 \pm 0.0914$ & $0.172 \pm 0.0126$ & $0.00915 \pm 0.00220$ & $0.0847 \pm 0.0135$ \\
\hline Highland Burgundy Red & $2.14 \pm 0.0489$ & $0.350 \pm 0.0102$ & $0.0360 \pm 0.00360$ & $0.0573 \pm 0.00957$ \\
\hline Kasta & $1.27 \pm 0.0530$ & $0.00126 \pm 0.000300$ & $0.0246 \pm 0.00235$ & $0.0972 \pm 0.00455$ \\
\hline Morada & $0.514 \pm 0.00984$ & $0.00686 \pm 0.00178$ & $0.0590 \pm 0.00425$ & $0.107 \pm 0.00612$ \\
\hline Morea & $0.400 \pm 0.0122$ & $0.0320 \pm 0.00955$ & $0.0292 \pm 0.00571$ & $0.0912 \pm 0.0219$ \\
\hline NK-08/349 & $0.376 \pm 0.0275$ & $0.0545 \pm 0.0163$ & $0.0236 \pm 0.00283$ & $0.0501 \pm 0.0144$ \\
\hline NK- $08 / 360$ & $0.140 \pm 0.0208$ & $0.000100 \pm 0.0000100$ & $0.0194 \pm 0.00152$ & $0.0704 \pm 0.0120$ \\
\hline NK-08/362 & $0.428 \pm 0.0252$ & $0.158 \pm 0.00460$ & $0.0326 \pm 0.00160$ & $0.0869 \pm 0.0182$ \\
\hline Purple Peruvian & $2.15 \pm 0.0102$ & $0.408 \pm 0.0170$ & $0.0188 \pm 0.00113$ & $0.0926 \pm 0.00973$ \\
\hline Rosa Roter & $1.09 \pm 0.0110$ & $0.0359 \pm 0.0 .06$ & $0.0341 \pm 0.00515$ & $0.0366 \pm 0.0149$ \\
\hline Rouge de Flandes & $1.81 \pm 0.0239$ & $0.270 \pm 0.00584$ & $0.0349 \pm 0.00155$ & $0.0677 \pm 0.0109$ \\
\hline Valfi & $0.521 \pm 0.0162$ & $0.123 \pm 0.00336$ & $0.0203 \pm 0.00223$ & $0.0589 \pm 0.0179$ \\
\hline Violet Queen & $2.78 \pm 0.0512$ & $1.33 \pm 0.0111$ & $0.0351 \pm 0.00117$ & $0.0671 \pm 0.0110$ \\
\hline Vitelotte & $1.64 \pm 0.0901$ & $0.436 \pm 0.00741$ & $0.0282 \pm 0.00484$ & $0.0931 \pm 0.0182$ \\
\hline LSD (0.05) & 0.107 & 0.0255 & 0.00475 & 0.0230 \\
\hline
\end{tabular}

786 LSD: Least Significance Difference.

787

788 
789 Table 3. Matrix for Pearson correlation coefficients $(r)$ showing the linear relationship 790 among total soluble phenolics (TSP), total monomeric anthocyanins (TMA), hydrophilic 791 antioxidant capacity measured by ABTS and DPPH (HAC), total carotenoid content (TC) 792 and vitamin $\mathrm{C}(\mathrm{VC})$.

\begin{tabular}{lllllll}
\hline & TSP & TMA & HAC.ABTS & HAC.DPPH & TC & VC \\
\hline TSP & 1.00 & & & & & \\
TMA & $0.789^{* * * *}$ & 1.00 & & & & \\
HAC-ABTS & $0.787^{* * * *}$ & $0.871^{* * * *}$ & 1.00 & & & \\
HAC-DPPH & $0.792^{* * * *}$ & $0.799^{* * * *}$ & $0.907^{* * * *}$ & 1.00 & & \\
TC & 0.0903 & 0.127 & 0.0371 & -0.0681 & 1.00 & \\
VC & -0.0466 & -0.0651 & -0.0225 & 0.111 & -0.0310 & 1.00 \\
\hline
\end{tabular}

793 
794 Table 4. Confusion matrix of the three groups - low content (LC), mid content (MC) and 795 high content (HC) - in the TSP, TMA and HAC PLS-DA model for Cal, CV and Pred.

796

797

\begin{tabular}{|c|c|c|c|c|c|}
\hline \multirow{5}{*}{ 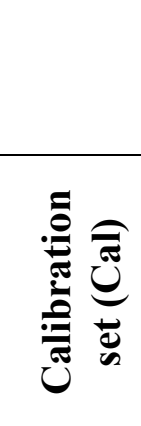 } & & & \multicolumn{3}{|c|}{ Actual Group (\%) } \\
\hline & & & $\mathrm{LC}$ & \multirow{2}{*}{\begin{tabular}{|l}
$\mathrm{MC}$ \\
2.47
\end{tabular}} & \multirow{2}{*}{$\begin{array}{l}\mathrm{HC} \\
0.00\end{array}$} \\
\hline & \multirow{9}{*}{ 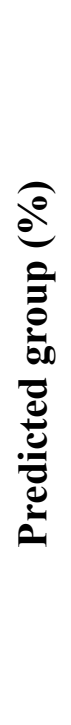 } & $\mathrm{LC}$ & 91.2 & & \\
\hline & & $\mathrm{MC}$ & 4.90 & 87.6 & 9.09 \\
\hline & & $\mathrm{HC}$ & 3.92 & 9.88 & 90.9 \\
\hline \multirow{3}{*}{ 岁总 } & & $\mathrm{LC}$ & 90.2 & 4.94 & 0.00 \\
\hline & & $\mathrm{MC}$ & 6.86 & 82.7 & 10.4 \\
\hline & & $\mathrm{HC}$ & 2.94 & 12.3 & 89.6 \\
\hline \multirow{3}{*}{ 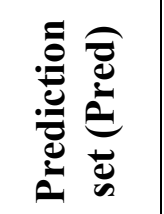 } & & $\mathrm{LC}$ & 97.6 & 0.00 & 3.85 \\
\hline & & $\mathrm{MC}$ & 2.38 & 83.8 & 19.2 \\
\hline & & $\mathrm{HC}$ & 0.00 & 16.2 & 76.9 \\
\hline
\end{tabular}

798

799

800

801

802

803

804

805

806

807

808

809

810

811

812

813

814

815

816

817

818

819

820

821 
822 Table 5. Confusion matrix of the three groups - low content (LC), mid content (MC) and 823 high content (HC) - in the TC PLS-DA model for Cal, CV and Pred.

\section{4}

825

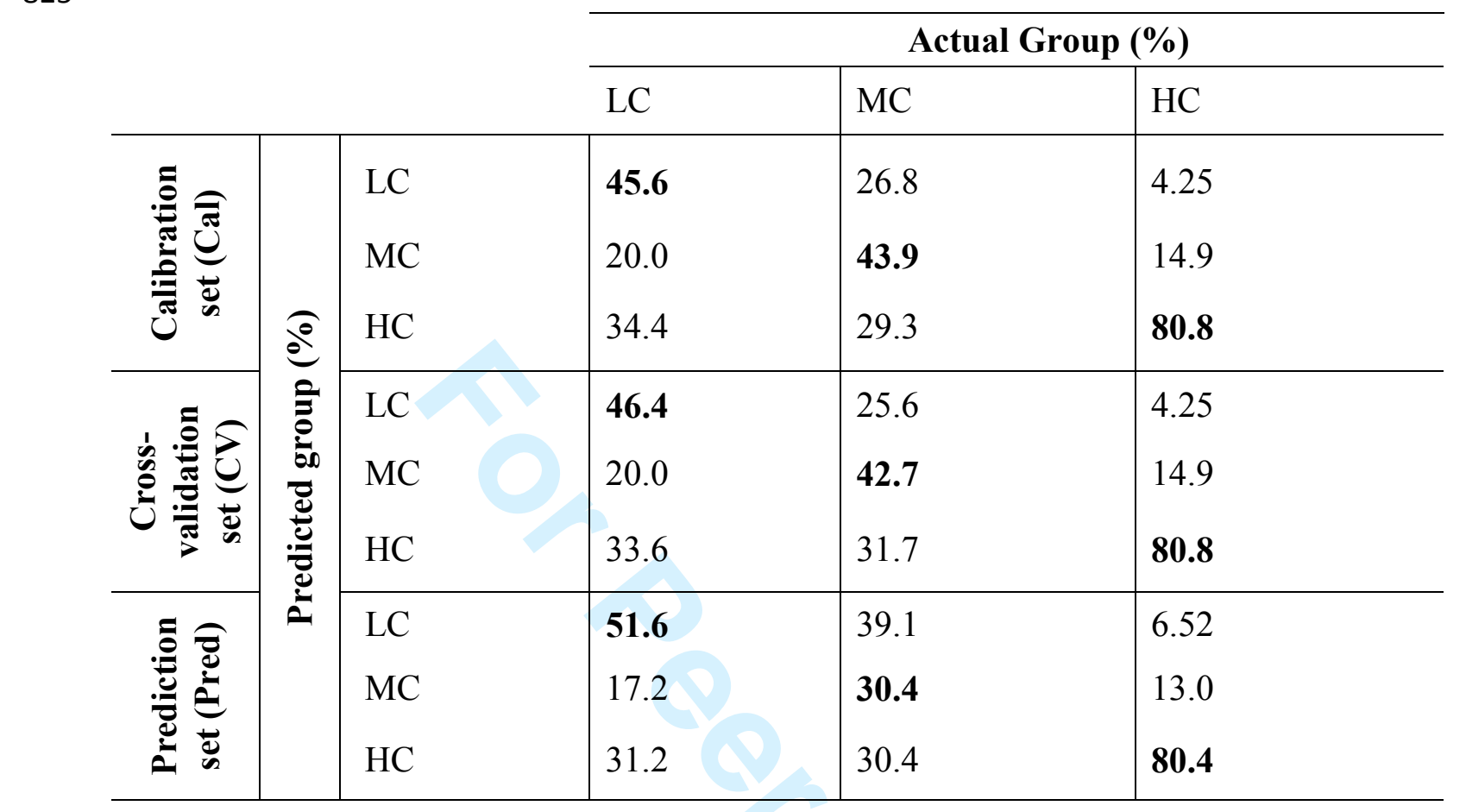

826 
831

TSP, TMA \& HAC content

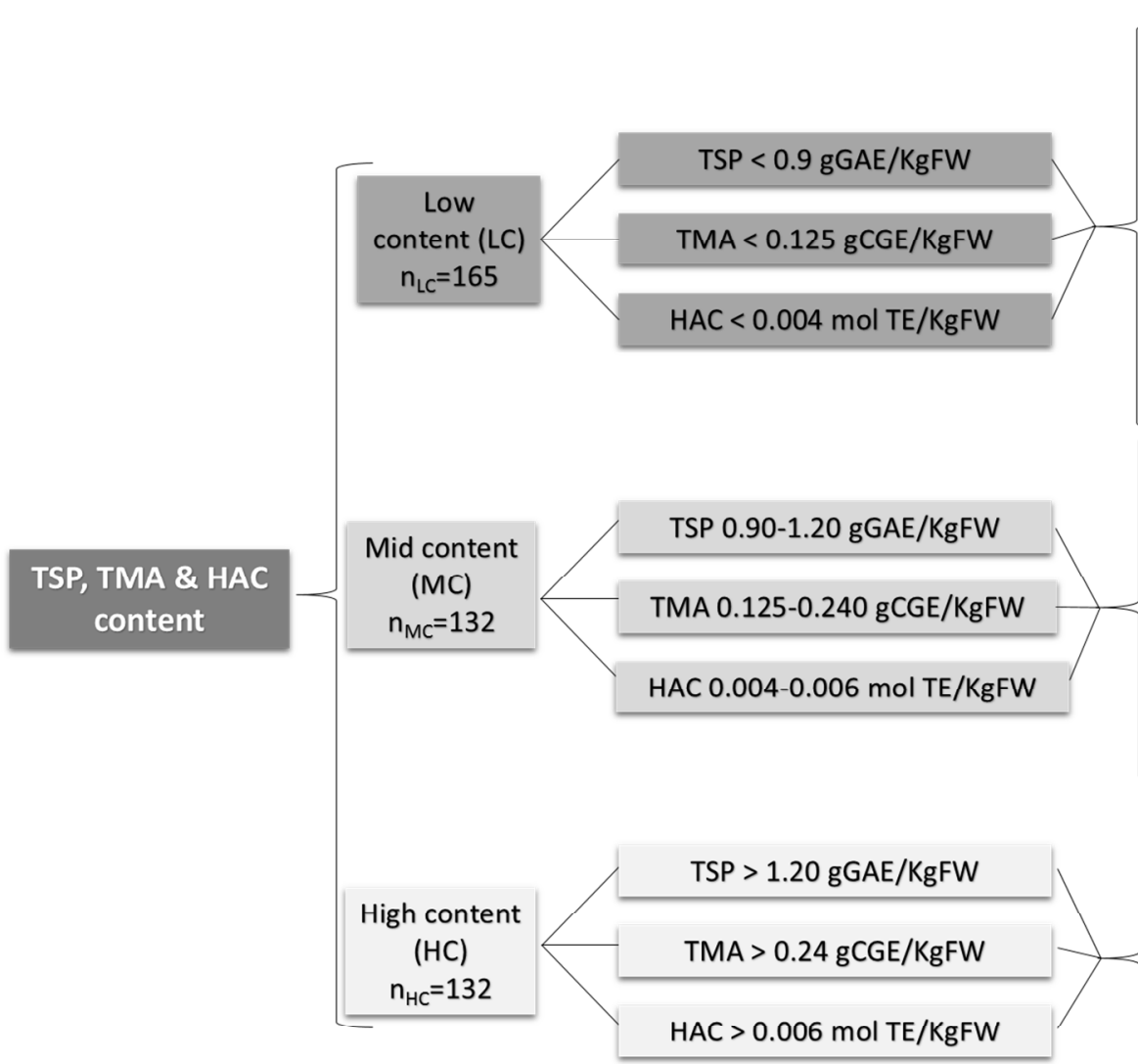

\begin{tabular}{|c|}
\hline Morada \\
\hline Morea \\
\hline Nk-08/349 \\
\hline Nk-08/360 \\
\hline Nk-08/362 \\
\hline Valfi \\
\hline Bleu de La Manche \\
\hline Blue Congo \\
\hline Blue Star \\
\hline British Columbia Blue \\
\hline Fenton \\
\hline Highland \\
\hline Purple Peruvian \\
\hline Rogue de Flandes \\
\hline Violet Queen \\
\hline Vitelotte \\
\hline
\end{tabular}

Fig.1 
841

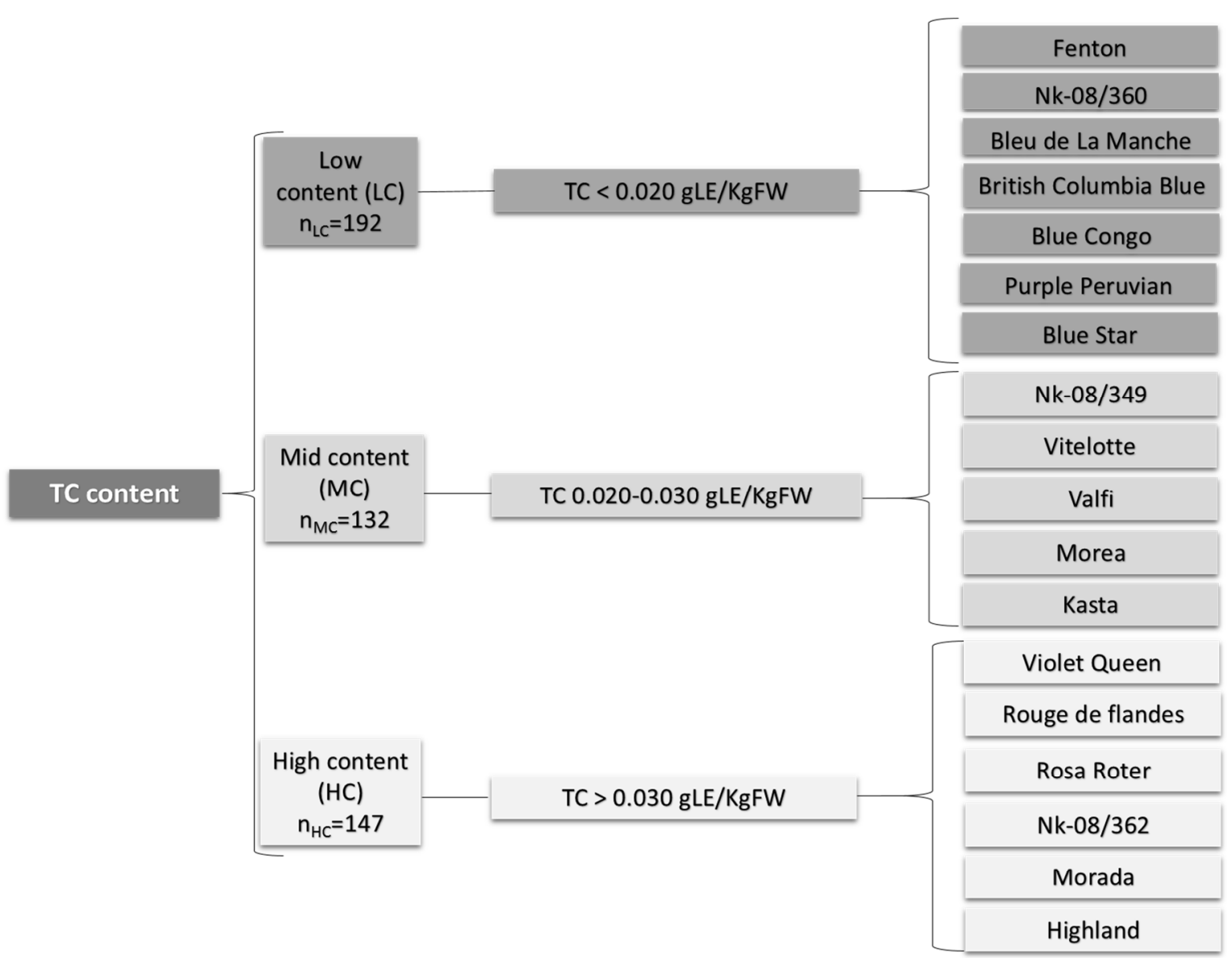

842

$843 \quad$ Fig. 2 


\section{VC content}

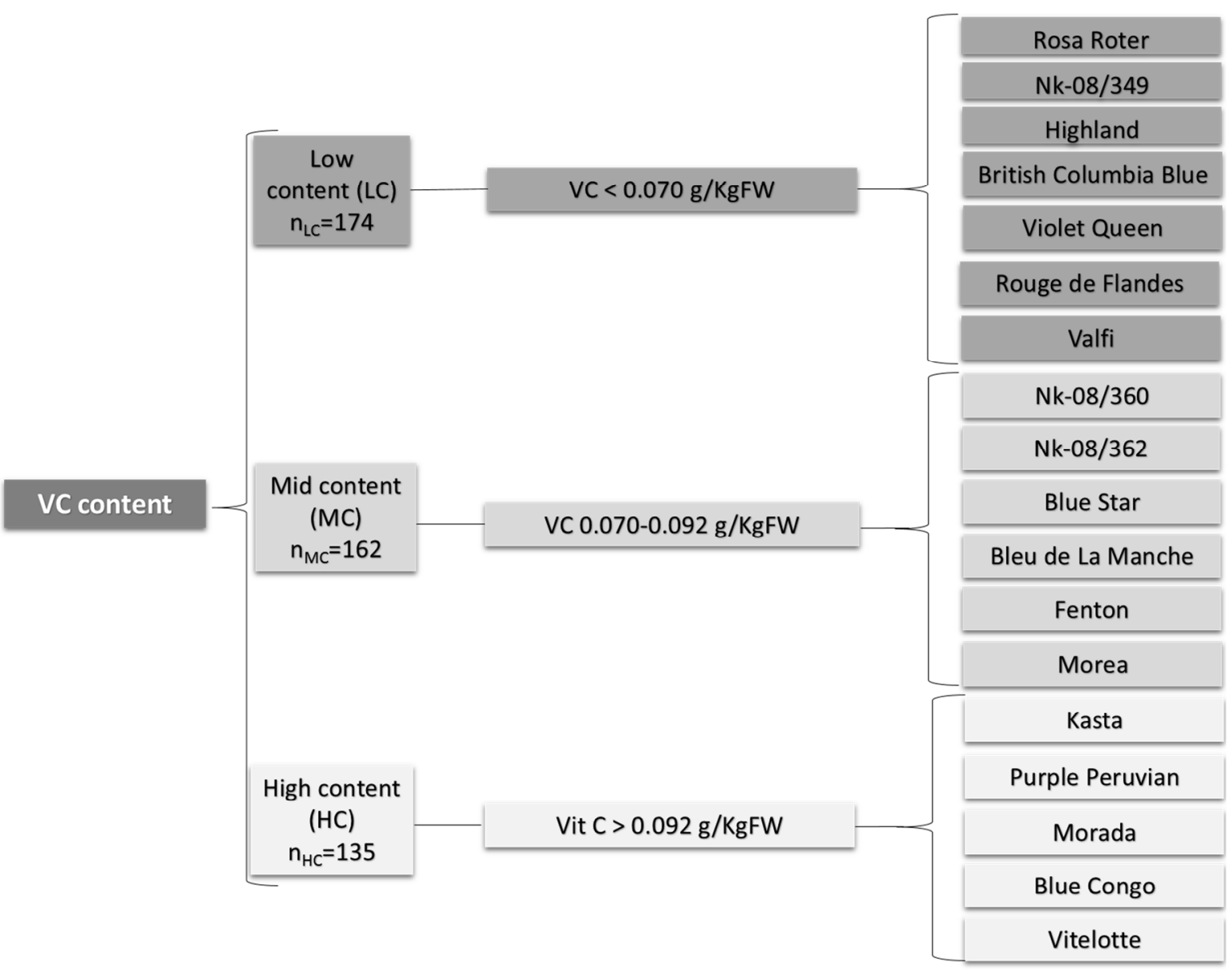

845

846

Fig. 3 


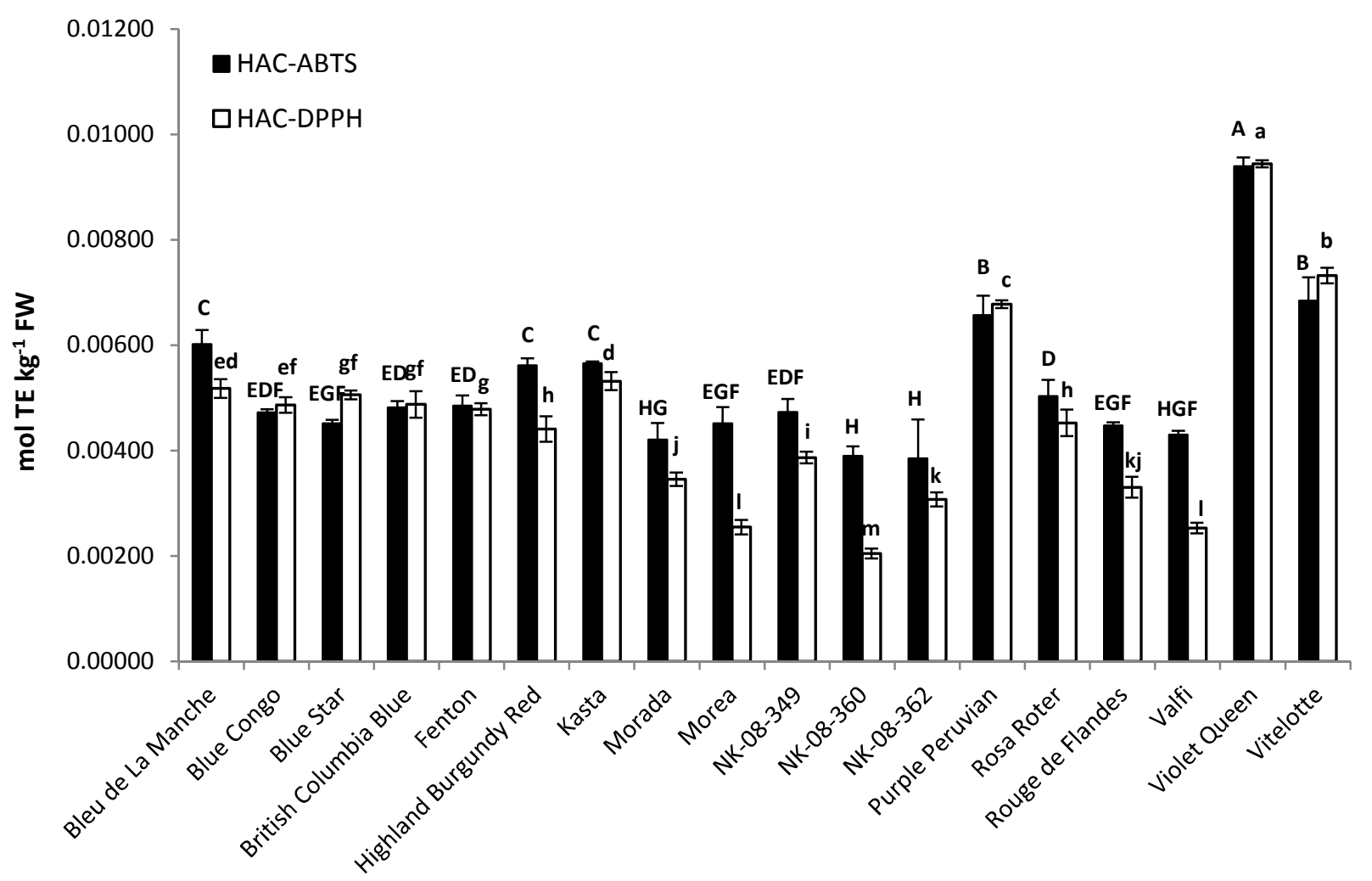

Cultivars or breeding lines
847

848

849

850

Fig.4 
852 a)

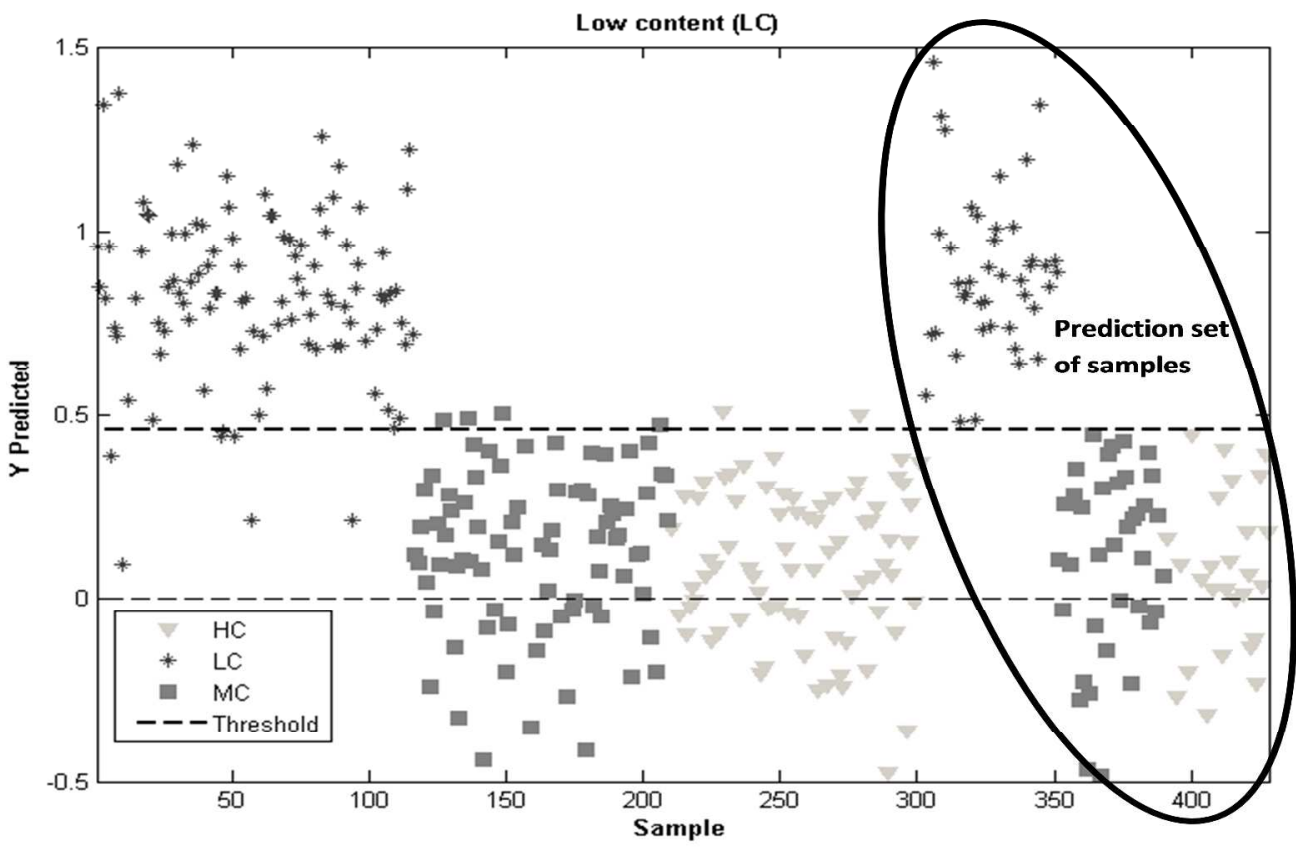

854 b)

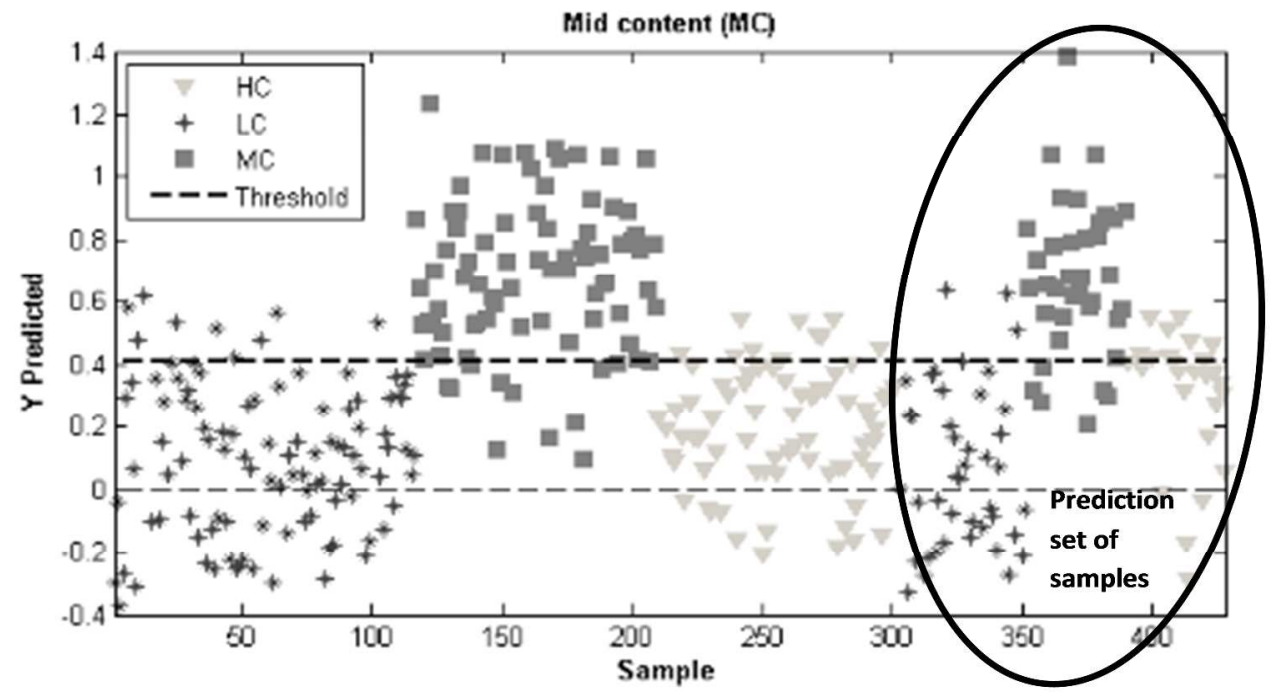

855

856 
857 c)

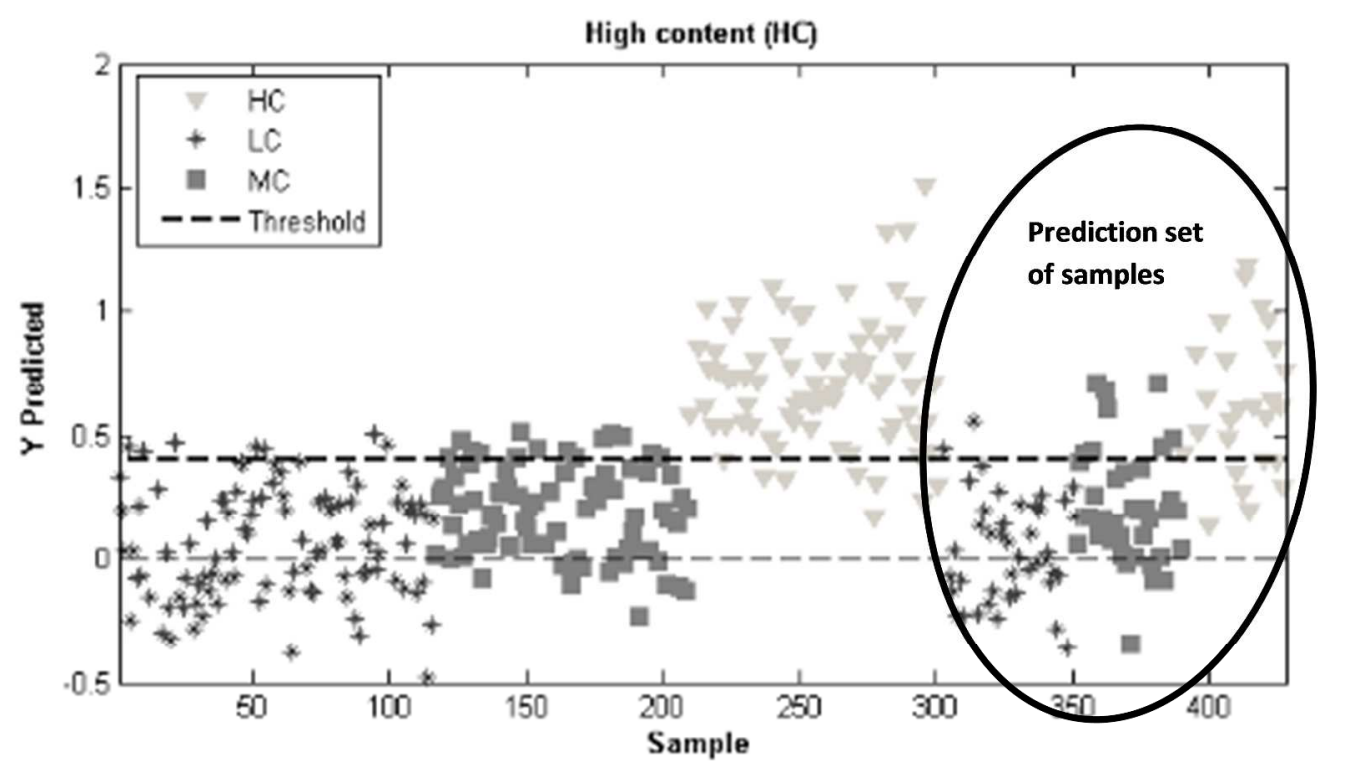

858

859

$860 \quad$ Fig.5

861

862 